\title{
1 Acute stress induces long-lasting alterations in the 2 dopaminergic system of female mice
}

3

4

Romy Wichmann ${ }^{1,5}$, Caitlin M. Vander Weele ${ }^{1,5}$, Ariella S. Yosafat ${ }^{1,5}$, Evelien H.S. Schut ${ }^{1,2}$, Jeroen P. H. Verharen ${ }^{1,3}$, Suganya Sridharma ${ }^{1}$, Cody A. Siciliano ${ }^{1}$, Ehsan M. Izadmehr ${ }^{1}$, Kathryn M. Farris $^{1}$, Craig P. Wildes ${ }^{1}$, Eyal Y. Kimchi ${ }^{1,4}$ and Kay M. Tye ${ }^{1,6}$

${ }^{1}$ The Picower Institute for Learning and Memory, Department of Brain and Cognitive Sciences, Massachusetts Institute of Technology, Cambridge, MA 02139, USA.

${ }^{2}$ Department of Cognitive Neuroscience, Radboud University Medical Center Nijmegen, Nijmegen, The Netherlands

${ }^{3}$ Department of Translational Neuroscience, Brain Center Rudolf Magnus, University Medical Center Utrecht, Utrecht, The Netherlands ${ }^{4}$ Department of Neurology, Massachusetts General Hospital, Boston, MA 02114, USA

${ }^{5}$ These authors contributed equally

${ }^{6}$ To Whom Correspondence Should be Addressed:

Kay M. Tye, PhD

Picower Institute for Learning and Memory

Department of Brain and Cognitive Sciences

77 Massachusetts Ave, Bldg-Rm 46-6263

Massachusetts Institute of Technology, Cambridge, MA 01239.

kaytye@mit.edu 


\section{Abstract}

55 Stress is a risk factor for many neuropsychiatric disorders, and the mesolimbic dopamine (DA)

56 pathway is a crucial node of vulnerability. Despite the high prevalence of stress-related

57 neuropsychiatric disorders in women, preclinical knowledge on the impact of stress on neural

58 circuitry has predominantly been acquired in males. Here, we examine how a non-social stressor

59 impacts the effect of DA neurotransmission on social and reward-related behaviors in female

60 mice. Acute stress exposure attenuated the anti-social effects of photoinhibiting ventral tegmental

61 area (VTA) DA neurons and transformed photoactivation of these cells into an anti-social signal.

62 Fast-scan cyclic voltammetry (FSCV) revealed an enhancement in optogenetically-induced DA

63 release after stress. 60 days after stress, mice showed distinct patterns of intra-cranial self-

64 stimulation of VTA DA neurons. Our results reveal the impact stress exerts on females and show

65 that neural and behavioral changes induced by acute stress exposure are still present months

66 later.

67

68

69 


\section{Introduction}

71 Stressors, or threats to an organism's physical or psychological homeostasis, recruit a

72 constellation of compensatory processes aimed at mitigating harm (Chrousos, 2009; Gold, 2015).

73 While these immediate physiological and cognitive responses may be adaptive, stress exposure,

74 when chronic or severe, can cause long-lasting alterations in brain structure and function, which

75 can translate into maladaptive behaviors later in life (Chetty et al., 2014; Koenig et al., 2011; Mah

76 et al., 2016; McEwen et al., 2015; Schneiderman et al., 2005). For example, stress is associated

77 with a number of negative outcomes experienced in adulthood, including an increased risk in the

78 development of several neuropsychiatric disorders (e.g., addiction, depression, anxiety, and

79 schizophrenia) (Mah et al., 2016; Piazza and Le Moal, 1998; Solomon, 2017). Although stress

80 and mental health disorders appear to be consistently linked, the effects of stress on subsequent

81 disease-relevant behaviors have been distressingly understudied in females (Goel and Bale,

82 2009).

Considerable evidence suggests that the neurochemical basis of many neuropsychiatric disease states involves a disruption of dopamine (DA) signaling (Nestler and Carlezon, 2006; Piazza and Le Moal, 1996; Russo and Nestler, 2013). While the mesolimbic DA system is historically thought to underlie appetitive motivation and reward-related processes (Schultz, 1998; Wightman and Robinson, 2002; Wise, 2008), there is a growing body of evidence for DA involvement in both acute and prolonged stress responses (Imperato et al. 1992; Di Chiara, Loddo, and Tanda 1999; Saal et al. 2003; Campi et al. 2014; See (Holly and Miczek, 2016) for extensive review of the current literature). For example, several studies have reported enhanced

91 DA neurotransmission during or immediately following stress exposure (Abercrombie et al., 1989;

92 Badrinarayan et al., 2012; Imperato et al., 1992; Mantz et al., 1989; Thierry et al., 1976; Tidey 93 and Miczek, 1996), and prior stress experience potentiates evoked DA release in response to 94 subsequent stress or electrical stimulation (Di Chiara et al., 1999; Yorgason et al., 2013, 2016). 95 Further, stress exposure also increases drug abuse vulnerability, drug seeking, and relapse 96 following abstinence (Dube et al., 2003; Koob and Volkow, 2016; Shaham et al., 2003; Sinha, 97 2008; Yorgason et al., 2016), and it is hypothesized that stress sensitizes the mesolimbic 98 dopaminergic system, thereby potentiating the rewarding properties of drugs of abuse (Johnston 99 et al., 2016; Lemos et al., 2012; Piazza and Le Moal, 1998; Saal et al., 2003). Despite this rich 100 literature, it is yet unknown how the stress-induced changes in DA signaling can alter disease101 relevant behaviors at different points in time following an acute stress exposure.

102 The effects of stress on DA and DA-modulated behaviors have been well characterized in 103 the male rodent brain (Cao et al., 2010; Chaudhury et al., 2013; Tye et al., 2013; Valenti et al., 
104 2012; Yorgason et al., 2013, 2016). However, there is limited knowledge of how stress affects the

105 female brain, despite evidence that sex strongly influences an individual's response to

106 environmental challenges (Cahill, 2006; Gruene et al., 2015; Taylor et al., 2000; Trainor, 2011).

107 Considering females exhibit higher sensitivity to stress (Carpenter et al., 2017; Dalla et al., 2005;

108 Handa et al., 1994; Lin et al., 2008), a higher prevalence for mood disorders (Bale and Epperson,

109 2015; Bangasser and Valentino, 2014; Bangasser and Wicks, 2017; Kessler, 2003), and

110 addiction-relevant behavior (Anker and Carroll, 2011; Calipari et al., 2017), it appears that this

111 understudied population is particularly at risk for maladaptive, stress-induced physiological and

112 behavioral alterations. Nonetheless, few studies have examined the basic characteristics of DA

113 signaling in females, and even fewer have also examined its interaction with stress (Campi et al.,

114 2014; Holly et al., 2012; Shimamoto et al., 2015; Trainor, 2011).

115 Impairments in social behavior represent a hallmark feature in a number of

116 neuropsychiatric diseases, including depression, anxiety and schizophrenia. Although many

117 factors contribute to the development of mood disorders, as stated above, stress can trigger the

118 onset and increase the risk for the development of these disorders (Mah et al., 2016; Piazza and

119 Le Moal, 1998; Solomon, 2017). Stress, especially when chronic, can reduce social motivation

120 and interactions in a variety of tests (Sandi and Haller, 2015), however a challenge is that many

121 of the studies examining the effects of stress on social behavior use a social defeat stressor (Cao

122 et al., 2010; Chaudhury et al., 2013; Krishnan et al., 2007), leaving the question of whether non-

123 social stressors can alter social behavior unanswered.

124 In this study, we demonstrate long-lasting changes in DA-modulation of social interaction,

125 and provide the first in vivo characterization of phasic DA release, following non-social stress in

126 female mice. We further investigated the consequences of these stress-induced alterations on

127 reward- and anxiety-related behaviors.

129 Results

5-day forced swim stress alters the effect of VTA DA neuron inhibition on social interaction

To determine whether stress changes the influence of DA neuron inhibition on social

133 interaction, female tyrosine hydroxylase $(\mathrm{TH})::$ Cre mice underwent a 5-day forced swim stress

134 exposure either 7 days before testing ("recent stress") or $~ 60$ days before testing ("remote stress")

135 in adulthood (mice were P97-99 during behavioral testing; Figure 1A-B). To enable

136 photoinhibition of VTA DA neurons, we injected an adeno-associated viral (AAV) vector carrying

137 a double-inverted open reading frame (DIO) construct allowing for cre-dependent expression of 
138 Halorhodopsin (eNpHR3.0) fused to enhanced yellow fluorescent protein (eYFP) and implanted

139 an optical fiber above the VTA (Figure 1C and Figure 1-figure supplement 1A-C).

140 To assay social behavior, mice were tested on a 2-day social interaction paradigm. Here,

141 an unfamiliar young female was introduced into the cage of the experimental mouse and VTA DA

142 neuron activity was inhibited in the experimental mouse during one testing session

143 (counterbalanced for order) (Figure 1D). Consistent with previous reports (Gunaydin et al 2014)

144 photoinhibition of VTA DA neurons reduced social interaction times in non-stressed controls

145 (Figure $1 \mathrm{E}-\mathrm{G}$ ). However, photoinhibition after recent and remote stress exposure did not induce

146 the same decrease in social interaction (Figure 1E-G). We also replicated a subset of these

147 experiments in dopamine transporter (DAT)::Cre mice (Figure 1F inset and Figure1-figure

148 supplement 1C-D).To test whether optically-induced changes in social interaction following stress

149 are restricted to the social realm or are more generalizable, mice were also tested in a novel

150 object assay (Figure $1 \mathrm{H}$ ). While stress experience recently increased novel object exploration

151 relative to non-stress mice, VTA DA photostimulation did not alter novel object exploration in any

152 group (Figure 1/-K). Other behaviors executed during social interaction and novel object

153 exploration, e.g. digging and rearing, remained unaltered by both photostimulation as well as

154 stress exposure (Figure 1-Figure supplement 1E-F).

155 To determine whether other factors, such as general anxiety level or locomotor alterations,

156 contributed to the reduction in social interaction behavior, we also tested mice in the elevated plus

157 maze as well as an open field assay (Calhoon and Tye, 2015; Carola et al., 2002; Pellow et al.,

158 1985). We did not detect differences between the effect of photoinhibition nor stress exposure

159 on anxiety-related behaviors (Figure 1-figure supplement 1G) and locomotion (Figure 1-figure

160 supplement $1 \mathrm{H}-\mathrm{I}$ ) did not produce detectable differences between stress exposures and

161 photostimulation.

163 Following stress, photostimulation of VTA DA neurons becomes an anti-social signal

164 A new cohort of TH::Cre female mice was injected with AAV-DIO-ChR2-eYFP and an optic fiber

165 was positioned over the VTA (a subset of these experiments were replicated in DAT::Cre mice

166 Figure 2-figure supplement 1A-D). Stress exposure did not affect baseline social interaction levels

167 and phasic photostimulation of VTA DA neurons in non-stressed females did not significantly alter

168 social interaction time (Figure 2A-C). However, photostimulation significantly reduced interaction

169 time in both recently- and remotely-stressed mice (Figure 2A-C), demonstrating a long-lasting,

170 stress-induced impact. The stress-induced changes of dopaminergic activation on behavior were

171 specific to social interaction, as photoactivation did again not modulate the effects of stress 
172 exposure on novel object exploration (Figure 2D-F), digging and rearing behaviors (Figure 2-

173 figure supplement 1E-F, anxiety-related behaviors (Figure 2-figure supplement 2G), or locomotion

174 (Figure 2-figure supplement 2H-I). Recent stress exposure did, however, increase novel object

175 exploration in recently stressed mice relative to non-stressed mice, independent of photoinhibition

176 (Figure 2D).

177 Importantly, dynamic changes during adolescence that influence fear extinction have been

178 reported (Pattwell et al., 2012). We next investigated whether the differences in the remote stress

179 group were related to the duration of time between stress exposure and testing or the

180 developmental stage during initial stress exposure. Thus, we included another group of mice

181 wherein the initial stress exposure was delivered in adulthood rather than adolescence, and kept

182 the duration of 60 days constant. We found that there was no difference between groups wherein

183 the stress exposure period was delivered during adolescence (P28-32) and adulthood (P86-90;

184 Figure 2-figure Supplement 2J). Although we did not experimentally deliver stress to the age-

185 matched controls (adulthood, non-stress group) we cannot rule out the possibility that there was

186 accumulation of stress across the lifetime of these animals.

DA receptor signaling in the NAC is necessary for VTA DA-mediated anti-social effects in

190 To verify whether DA transmission within the NAc is required to mediate the effects of VTA

191 photostimulation on social interaction, we bilaterally infused a D1-type and D2-type DA receptor

192 antagonist cocktail in the NAc prior to photostimulation (Figure 3A and Figure 3-figure supplement

193 1A-B). DA receptor blockade in the NAc attenuated the light-induced anti-social effects observed

194 after stress exposure (Figure 3B-C). These findings are consistent with our hypothesis that DA

195 transmission from the VTA to the NAc is necessary to induce the changes seen in social

196 interaction upon light stimulation. Although we observed a significant increase of locomotion upon

197 light stimulation in our vehicle-treated mice (Figure 3D), this was not correlated with light-induced

198 changes in social interaction (Figure 3E). Likewise, no correlation was observed between

199 changes in locomotion ( $\Delta$ locomotion) and changes in social interaction ( $\Delta$ social) in drug-treated

200 females (Figure 3F). Thus changes observed in locomotion do not appear to modulate the

201 changes observed in social interaction behavior.

203 Stress facilitates optically-induced DA-release in NAc over prolonged periods of time

204 To investigate possible long-term alterations in DA neurotransmission due to stress exposure, we

205 performed in vivo fast-scan cyclic voltammetry (FSCV) to monitor DA release within the NAc 
206 evoked by optical stimulation of VTA DA neurons (Figure 4A and Figure 4-figure supplement 1A207 B). Optical stimulation (8 pulses at $30 \mathrm{~Hz}, 5 \mathrm{~ms}$ pulses, $20 \mathrm{~mW}$ of $473 \mathrm{~nm}$ laser light) of VTA DA 208 neurons induced greater extracellular DA ([DA]) release in the NAc of both recently and remotely 209 stressed mice, compared to non-stressed controls (Figure 4B-D). DA reuptake, measured as tau, 210 was not effected in any of the treatment groups (Figure 4E) and was independent of peak release 211 (Figure 4F). With higher intensity photostimulation (90 pulses at $30 \mathrm{~Hz}, 5 \mathrm{~ms}$ pulses, $20 \mathrm{~mW}$ of $212473 \mathrm{~nm}$ laser light) a similar pattern of DA release differences between groups was observed 213 (Figure 4G-I); however again no detectable differences in reuptake were observed (Figure 4J-K). 214 Importantly, DA release followed the phasic stimulation parameters (8 pulses at $30 \mathrm{~Hz}$, every 5 215 seconds) used during behavioral experiments (Figure 4-figure supplement 1C).

216 To examine how stress-induced alterations in DA signaling influence the ability of VTA DA 217 photostimulation to serve as a primary reinforcer (Witten et al., 2011), we assessed the effects of 218 optically-stimulated DA release on response rate to intracranial self-stimulation (ICSS) of VTA DA 219 neurons. Interestingly, the remote stress group showed significantly different ICSS performance 220 relative to the non-stress group, reflected as either increased or decreased nosepoke responding 221 for photostimulation, depending on the stimulation parameters (Figure 4L-M). Specifically, while 222 all treatment groups showed robust self-stimulation, remotely-stressed mice made significantly 223 more nose-poke responses for light-stimulation of 8 pulses at $30 \mathrm{~Hz}$ for each nosepoke when 224 compared to non-stressed mice (Figure 4L). In contrast, when nosepokes were paired with 90 225 pulses at $30 \mathrm{~Hz}$, remotely-stressed mice made significantly fewer nosepoke responses relative to 226 non-stressed mice (Figure 4M). These data are consistent with the notion that the relationship 227 between DA and behavior is nonlinear. 


\section{Discussion}

233 We investigated how 5 days of stress exposure affects optical manipulation of DA cell 234 bodies residing in the ventral tegmental area (VTA) during social behaviors as well as DA 235 neurotransmission over prolonged periods of time. Specifically, photoinhibition of VTA DA 236 neurons during a social interaction assay resulted in an anti-social effect in non-stressed control 237 females, an effect that was blocked in stressed females. Conversely, prior stress experience 238 resulted in an anti-social effect during photoactivation of VTA DA neurons, an effect that was 239 attenuated by intra-NAc DA receptor blockade. Importantly, these effects appear to be specific to 240 the social domain because VTA DA manipulations did not differentially alter novel object 241 exploration, general anxiety levels, or locomotion. Further, both remotely and recently stressed 242 mice exhibited amplified peak DA release in the NAc produced by optical stimulation of VTA DA 243 neurons in vivo. To assess the impact of stress-evoked alterations in DA signaling on reward244 relevant behaviors, we examined how optical activation of VTA DA neurons affects social 245 interaction and intra-cranial self-stimulation (ICSS). Considering that VTA DA neurons have been 246 implicated in social reward, our social data alone may suggest that stress attenuates the 247 reinforcing properties of VTA DA activation. However, remotely stressed individual exhibited 248 higher ICSS response rates compared to non-stressed controls when stimulated with a low 249 intensity, but a lower response rate when stimulated with a higher intensity. This suggests that 250 stress may alter DA-mediated reinforcement in a stimulus-dependent manner.

251 DA neurotransmission regulates motivated behaviors (Wightman and Robinson, 2002).

252 Phasic DA release in the NAc signals unconditioned reward delivery (Aragona et al., 2008; Day 253 et al., 2007; Roitman et al., 2008), reward-predictive cues (Roitman et al., 2004) and promotes 254 reward-seeking (Phillips et al., 2003). As such, we investigated the effects of stress-induced 255 alterations in phasic DA release on reward-related behaviors. We first examined the effects on 256 social interaction since affiliative social interaction is sex-specific (Bergan et al., 2014; Dulac and 257 Kimchi, 2007), stress-sensitive, and recruits the mesolimbic DA pathway (Campi et al., 2014; 258 Chaudhury et al., 2013; Gunaydin et al., 2014; Krishnan et al., 2007; Robinson et al., 2002). Here, 259 we found that stress produces social avoidance upon phasic VTA DA stimulation in both recently 260 and remotely stressed females, an effect which relied upon DA receptor activation in the NAc. 261 Previous work has shown a similar decrease in social interaction after administration of a high 262 dose of DA-receptor agonist into the NAc of female mice (Campi et al., 2014) as well as a negative 263 correlation between VTA firing rate and social interaction time in male mice (Cao et al., 2010). 264 Together with our data this suggests that amplified dopaminergic activity promotes social 265 avoidance. This theory can be consolidated with our results employing halorhodopsin-induced 
266 inhibition of VTA DA neurons during our social interaction task. Here, stress exposure prevented 267 the social aversion optically triggered under non-stress conditions.

268 Our results go beyond previous literature in several ways, and highlight the exquisite 269 sensitivity of the female dopaminergic system to stress. Further, our novel non-social stress 270 paradigm did not significantly alter baseline responses to social interaction. Many studies report 271 social avoidance after chronic social defeat stress, a model that has great relevance to humans 272 (Cao et al., 2010; Chaudhury et al., 2013; Krishnan et al., 2007; Trainor et al., 2011). Acute social 273 isolation produces a rebound of social interaction upon reintroduction to social agents in rats 274 (Niesink and Van Ree, 1982; Panksepp and Beatty, 1980; Varlinskaya et al., 1999). Consistent 275 with our results (Figure $1 \mathrm{l}$ and Figure 2D), chronic social isolation of rats has produced greater 276 sensitivity to novelty in addition to changes in dopaminergic function in the NAc (Lapiz et al., 277 2003). This study complements existing studies by examining social interaction following an 278 acute non-social stress exposure, tackling a distinct condition with equal relevance to the human 279 condition. Indeed, our data are consistent with reports that non-social stressors do not affect later 280 social behavior, while social stressors decrease social behavior (Venzala et al., 2013). The type, 281 duration and severity of stressors should also be considered, as not all stressors are the same 282 (Valenti et al., 2012).

283 Our findings demonstrate the nonlinearity of the relationship between dopamine release 284 and reward-related behavior. As the interval between stress and testing increased, the 285 enhancement in dopamine release was greater (Figure $4 \mathrm{~A}-\mathrm{K}$ ). However, the relationship 286 between the interval between stress and testing was dependent on the stimulation parameters, 287 as remotely stressed animals had increased responding in ICSS for 8 pulses per response, but 288 decreased responding in ICSS for 90 pulses per response (Figure $4 \mathrm{~L}$ and $\mathrm{M}$ ). We speculate that 289 these findings have relevance to the striking comorbidity of addiction and neuropsychiatric mood 290 disorders (Brady and Sinha, 2005; Kessler et al., 1994), both of which are potentiated by stress. 291 Cocaine users, for example, show diminished emotional engagement, have fewer social contacts, 292 and have difficulty feeling empathy (Preller et al., 2014). Thus, stress-induced neuroadaptations 293 in the reward system may alter reward processing such that the motivational value of drug, or in 294 our case optical stimulation, is enhanced whereas the value of nondrug rewards, such as social 295 interaction, is reduced (Volkow et al., 2011).

296 Indeed, stress induces similar long-term adaptations within the VTA-NAc pathway as seen 297 after chronic drug abuse (Nestler 2006; Saal 2003; Ortiz 1996). Likewise, our new 5-day swim 298 stress appears to induce long-lasting adaptations in the VTA-NAc pathway that sensitizes 299 individuals to subsequent manipulations of this system and contributes to behavioral 
abnormalities. It is also interesting to note that the only difference observed between our two stress groups (recent vs. remote) was intra-cranial self-stimulation response rates for VTA DA photostimulation. Considering stress-evoked elevations in drug self-administration dissipate within 24 hours and then re-emerges after a time interval of days to weeks (Haney et al., 1995; Logrip et al., 2012; Lowery et al., 2008), it is possible that the differential reward sensitivity we observed between stress groups may result from a similar stress-mediated time course.

Our results are consistent with a vast literature showing that stressors alter the mesolimbic DA pathway and DA-mediated behaviors (Cabib and Puglisi-Allegra, 1996; Cao et al., 2010; Chaudhury et al., 2013; Di Chiara et al., 1999; Fone and Porkess, 2008; Imperato et al., 1992; Kalivas and Duffy, 1995; Krishnan et al., 2007; Laman-Maharg and Trainor, 2017; Tidey and Miczek, 1996; Valenti et al., 2012). For example, animals who experience early life stress exhibit behavioral hyperactivity in response to DA agonists (Brake et al., 2004; Lovic et al., 2006; Matthews and Robbins, 2003), suggesting stress induces a hyperdopaminergic state. Indeed, stress amplifies electrically- and stress-evoked phasic DA release (Brake et al., 2004; Karkhanis et al., 2016; Yorgason et al., 2013, 2016), but does not alter resting basal DA levels (Di Chiara et al., 1999; Luine, 2002). However, as previously mentioned, many of these studies were conducted in male rodents despite clear sex-dependent physiological and behavioral responses to stress (Gruene et al., 2015; Ter Horst et al., 2009; Trainor, 2011). In contrast to male rodents, females exhibit enhanced basal DA level in adulthood after early life stress (Afonso et al., 2011; Shimamoto et al., 2011; Thomas et al., 2009) and show potentiated psychomotor responses to DA agonists (Thomas et al., 2009). Although other variables (e.g., type, duration, and severity of the stressor, time since stress experience, etc.) may contribute to the observed differences, conclusions are difficult to draw given the paucity of literature examining neurochemical changes in the female brain following stress.

Our testing schedule allowed for the assessment of the consequences of recently and remotely experienced stress. We observed amplification of peak evoked DA release in recently stressed females. Additionally, our 5-day stressor experienced remotely evoked a remarkably similar pattern of DA neurotransmission dynamics in females as $\sim 50$ days of social isolation in males (Yorgason et al., 2016). Our data indicate that even a relatively short stressor can produce profound and long-lasting changes in the female DA system. While several studies report enhanced DA neurotransmission in males during or immediately following various stressors (Abercrombie et al., 1989; Di Chiara et al., 1999; Imperato et al., 1992; Saal et al., 2003; Tidey and Miczek, 1996), the long-term consequences we observed in females after several days of forced swim stress has not been observed in males (Lemos et al., 2012). 
When taken together with previous work (Duchesne et al., 2009; Lemos et al., 2012), our data suggest that the female mesolimbic DA pathway may be more sensitive to stress, and may therefore exhibit stress-induced DA alterations that do not lead to behavioral impairments in males. While this is tempting to speculate in the light of female vulnerability to neuropsychiatric disorders (e.g., anxiety, depression, and addiction) (Kessler, 2003; Kessler et al., 1994), there are several differences in key variables between these studies (stressor type, duration, and the neurochemical recording preparation). Future studies should investigate stress-induced DA neurotransmission patterns in identical experimental conditions in both sexes.

In addition to the careful consideration of experimental conditions, we also wish to emphasize the heterogeneity of the dopaminergic system. For example, acute social isolation increases subsequent social interaction and potentiates dorsal raphe nucleus DA neurons (Matthews et al., 2016), which points to the heterogeneity of the DA system. Even within the VTA, 346 there is substantial heterogeneity in the function of DA neurons (Lammel et al., 2011, 2012).

347 Another caveat is that not all transgenic mouse lines show the same expression patterns, which 348 is why we included both TH::Cre and DAT::Cre mouse lines, which show distinct expression 349 patterns in the VTA (Lammel et al., 2015; Stuber et al., 2015).

In summary, we find that stress experience can produce long-lasting alterations in the mesolimbic DA system and promote behavioral adaptations revealed upon stimulation of this

352 system in females. Although stress-induced circuit adaptations were often not visible at baseline, 353 their effects became unmasked when the system was pushed to its limits. This fits with a model 354 adapted from Shansky and Lipps (Shansky and Lipps, 2013) wherein an optimal level of DA 355 neuron activity promotes social interaction whereas both sub- and supra-optimal levels of DA 356 neurotransmission would reduce social interaction (Arnsten, 1997, 2009; Yerkes and Dodson, 357 1908). These findings highlight the sensitivity of the female DA system to stress and could have 358 relevance for this population's increased susceptibility for neuropsychiatric disorders and 359 addiction. 


\section{Material and Methods}

\section{Animals}

Female heterozygous tyrosine hydroxylase (TH)::IRES-Cre transgenic mice were used for all experiments. A subset of experiments was repeated in female heterozygous dopamine transporter (DAT)::Cre transgenic mice. At P21 all mice were transported from the breeding facility to the experimental facility and were housed on a reverse 12 hour light/dark cycle with food and water ad libitum for the rest of the experimental timeline. All mice were group-housed in pairs of 2-5. Mice were randomly assigned to an exposure group (non-stress, recent stress, or remote stress) and mice housed together were always subjected to the same exposure. Remote stress was performed between P28 and P32 and recent stress between P86 and P90. Behavioral testing occurred around P97 (Figure 1A). An additional subgroup of females $(n=10)$ were exposed to adult remote stress between P86-P90. Those mice were then tested around P155 together with a small cohort of non-stressed mice $(n=8)$. All mice were naïve before any experimental procedure. No animals were reused from other studies. All experimental protocols were approved by the MIT Institutional Animal Care and Use Committee in accordance with National Institutes of Health guidelines.

\section{Stereotaxic virus injection and optical fiber implantation}

Mice ( 8-9 weeks of age) were anesthetized with isoflurane (5\% for induction, $1.5-2 \%$ after) and placed in a stereotaxic frame on a heat pad. A $10 \mu \mathrm{l}$ Nanofil syringe with a 33 gauge beveled microinjection needle was used to infuse virus with a microsyringe pump and its controller. Virus was infused at a rate of $100 \mathrm{nl}$ per min. Following infusion, the needle was raised $50 \mu \mathrm{m}$ and then kept in place for an additional 10 min before being slowly withdrawn. All stereotaxic coordinates are relative to bregma. For photoactivation, voltammetry and pharmacological experiments, mice were unilaterally injected at two sites in the VTA (-3.2 to $-3.25 \mathrm{~mm}$ anteroposterior (AP); $0.35 \mathrm{~mm}$ mediolateral (ML); -4.25 and $-4.1 \mathrm{~mm}$ dorsoventral (DV)) with a total of $1.4 \mu$ l of virus $\left(\mathrm{AAV}_{5}-\mathrm{EF} 1 \mathrm{a}-\right.$

388 DIO-ChR2(H134R)-eYFP; UNC Viral Core; Chapel Hill, NC). An optical fiber (200-300 $\mu$ core,

389 0.22-0.37 numerical aperture [NA], Thorlabs, Newton, NJ, USA) was unilaterally implanted over 390 the ventral tegmental area (VTA; -3.25 mm AP; $0.35 \mathrm{~mm} \mathrm{ML}$ and $-3.75 \mathrm{~mm} \mathrm{DV}$ ) and secured to 391 the skull using a base layer of adhesive dental cement (C\&B Metabond; Parkell, Edgewood, NY) 392 followed by a second layer of cranioplastic cement (Ortho-Jet; Lang Dental, Wheeling, IL). For 393 photoinhibition experiments the same amount of virus (AAV 5 -EF1a-DIO-eNpHR3.0-eYFP; UNC 394 Viral Core; Chapel Hill, NC), was injected at two sites in the VTA (-3.25 mm AP; 0.00 to 0.015 
$395 \mathrm{~mm} \mathrm{ML;} \mathrm{-4.25} \mathrm{and}-4.1 \mathrm{~mm} \mathrm{DV}$ ). The optical fiber was positioned between the 2 hemispheres

396 medially above the VTA (-3.25 mm AP; $0.00 \mathrm{~mm} \mathrm{ML}$ and -2.5 to $-3.5 \mathrm{~mm} \mathrm{DV})$ and secured in the

397 same way as above.

Animals for pharmacological manipulations were, after 4 weeks of viral expression, additionally

400 implanted with bilateral guide cannulae ( $5 \mathrm{~mm}$, PlasticsOne, Roanoke, VA) over the nucleus ac-

401 cumbens (+1.35 mm AP; $\pm 0.6 \mathrm{~mm} \mathrm{ML}$ and $-3.0 \mathrm{~mm} \mathrm{DV})$. Cannulae were secured in the same

402 way as above. The incision was closed with sutures and mice were given a subcutaneous injec-

403 tion of Meloxicam $(1.5 \mathrm{mg} / \mathrm{kg})$ and saline $(\sim 1 \mathrm{ml})$ prior to recovery under a heat lamp. All behavioral

404 experiments were conducted 4-6 weeks after surgery.

\section{Swim stress}

407 We intensified a modified forced swim stress paradigm previously shown to produce escalating 408 immobility across sessions indicative of intensified expression of behavioral despair (Porsolt 409 1977; McLaughlin et al 2003, Bruchas et al 2007) and modulated responses in the dopaminergic 410 system (Lemos et al 2012). Mice in the recent and remote stress group were subjected to 5 day 411 swim stress in which they were exposed to a $15 \mathrm{~min}$ swim session on day 1, 3, and 5 and four 412 swim sessions of $6 \mathrm{~min}$ each separated by $6 \mathrm{~min}$ of rest on day 2 and 4 (Figure1B). Water tem413 perature was maintained at $24 \pm 1{ }^{\circ} \mathrm{C}$. After removal from water, mice were returned to their 414 homecage and allowed to recover under a heat lamp for $30 \mathrm{~min} .6 \mathrm{mice}$ in the recent stress group 415 underwent a 2 day forced swim stress instead of the described 5 days. Difference score values 416 of these animals were not significantly different and all mice were pooled into the recent stress 417 group subsequently.

\section{Fast-Scan-Cyclic Voltammetry (FSCV)}

$420 \mathrm{TH}:$ :Cre mice, which had received an injection of $A A V_{5}-E F 1 a-D I O-C h R 2(H 134 R)-e Y F P$ in the 421 VTA, as described above, were given at least 4 weeks for viral expression before recording 422 experiments. Each carbon-fiber electrode used was pre-calibrated in known concentrations of DA $423(250 \mathrm{nM}, 500 \mathrm{nM}$, and $1 \mu \mathrm{M})$ in flowing artificial cerebral spinal fluid. Calibration data were used 424 to convert in vivo signals to changes in DA concentration using chemometric, principal component 425 regression, and residual analyses (Badrinarayan et al., 2012) using a custom LabView program 426 (provided by R. Keithley). Anesthetized in vivo FSCV experiments were conducted similar to those 427 previously described (Matthews, 2016; Nieh et al., 2016). Briefly, mice were anesthetized with 428 urethane $(1.5 \mathrm{~g} / \mathrm{kg}$; IP) and placed in a stereotaxic frame. Craniotomies were performed above 
429 the NAc (+1.4 mm AP; $0.7 \mathrm{~mm} \mathrm{ML),} \mathrm{VTA} \mathrm{(-3.25} \mathrm{mm} \mathrm{AP;} 0.35 \mathrm{~mm} \mathrm{ML),} \mathrm{and} \mathrm{contralateral} \mathrm{cortex.}$

$430 \mathrm{An} \mathrm{Ag} / \mathrm{AgCl}$ reference electrode was implanted in the contralateral cortex and a $300 \mu \mathrm{m}$ optical

431 fiber was implanted above the VTA (-3.75 mm DV). Both implants were then secured to the skull

432 with adhesive cement (C\&B Metabond; Parkell, NY, USA). A glass-encased carbon fiber

433 electrode ( 120 $\mu \mathrm{m}$ in length, epoxied seal) was lowered into the NAc (DV: $-2.8 \mathrm{~mm}$ from brain

434 surface) for electrochemical recordings. Electrodes were allowed to equilibrate for $20 \mathrm{~min}$ at 60

$435 \mathrm{~Hz}$ and $10 \mathrm{~min}$ at $10 \mathrm{~Hz}$. Voltammetric recordings were collected at $10 \mathrm{~Hz}$ by applying a triangular

436 waveform $(-0.4 \mathrm{~V}$ to $+1.3 \mathrm{~V}$ to $-0.4 \mathrm{~V}, 400 \mathrm{~V} / \mathrm{s})$ to the carbon-fiber electrode versus the $\mathrm{Ag} / \mathrm{AgCl}$

437 reference. Electrodes were lowered in $200 \mu \mathrm{m}$ steps until a change in current $>1.0 \mathrm{nA}$ (minimum

438 criteria for recording) was evoked by optical stimulation of the VTA using 8 or 90 pulses of 473

$439 \mathrm{~nm}$ light (20 mW, $5 \mathrm{~ms}$ pulse duration) at $30 \mathrm{~Hz}$, delivered via a DPSS laser and controlled using

440 a Master-8 pulse generator. Data were collected using Tarheel CV (Chapel Hill, NC, USA) in 60s

441 files with the stimulation ( $8 \mathrm{p}$ or $90 \mathrm{p}$ ) onset occurring $5 \mathrm{~s}$ into the file. Files were collected with a

$44260 \mathrm{~s}$ inter-recording interval and background subtracted at the lowest current value prior to

443 stimulation onset. Light-evoked signals maintained characteristic cyclic voltammograms for DA,

444 with oxidation and reduction peaks at $\sim+0.65 \mathrm{~V}$ and $\sim-0.2 \mathrm{~V}$, respectively. In order to sample DA

445 release in several subregions of the NAc, 1-3 recordings locations (separated by $>200 \mu \mathrm{m}$ ) were

446 acquired per mouse within the same DV track. Locations which supported less than $1.0 \mathrm{nA}$ of 447 optically evoked change in current were discarded.

448 Following recordings, mice were transcardially perfused with 4\% PFA and processed using im449 munohistochemical techniques (described below). Evoked DA release was quantified by calcu450 lating the peak evoked release and area under the curve (10 s starting at stimulation onset; i.e., $4515-15 \mathrm{~s}$ ) for each recording. The time constant tau was defined as the time to clear two-thirds of 452 the evoked DA signal and was used as a measure of DA reuptake. 2 recordings sites from remote 453 stress mice were excluded from reuptake analysis, due to no baseline return. Data were analyzed 454 using a custom LabView program (provided by R. Keithley) and Demon Voltammetry and Analysis 455 software (Wake Forest University).

\section{Behavioral assays}

457 All behavioral tests were performed at least 4 weeks following viral injection to allow sufficient 458 time for transgene expression. Mice were tested during the dark phase and allowed to acclimate 459 to the behavioral testing room for at least $1 \mathrm{~h}$ prior to testing. Mice were handled and connected 460 to an optical patch cable for at least 3 days before being subjected to any behavioral assay. All 
461 behavioral tests were recorded by a video camera located directly above the respective arena.

462 The EthoVision XT video tracking system (Noldus, Wageningen, Netherlands) was used to track

463 mouse location, velocity, and movement of head, body, and tail. All measurements displayed are

464 relative to the center of the mouse body.

465 Social Interaction assay: Social Interaction in the homecage was examined as previously de466 scribed (Felix-Ortiz and Tye, 2014; Felix-Ortiz et al., 2016; Gunaydin et al., 2014). All cagemates 467 were temporarily moved to a holding cage and the experimental mouse was allowed to explore 468 its homecage freely for $1 \mathrm{~min}$ (habituation). A novel young (3-5 weeks of age) female C57BL/6 469 mouse was then introduced into the cage and the two mice were then allowed to interact freely 470 for $3 \mathrm{~min}$ (test session). Each experimental mouse underwent two social interaction tests sepa471 rated by 24 hours, with one intruder paired with optical stimulation and a different one with no 472 stimulation. Groups were counterbalanced for order of light stimulation. All behaviors were video 473 recorded and analyzed by 2 experimenters blind to the testing condition using ODLog software 474 (Macropod software). Individual results were then averaged. The overall score of social interaction 475 was defined as any period of time in which the experimental mouse was actively investigating the 476 intruder, including behaviors such as face or body sniffing, anogenital sniffing, direct contact, and 477 close following $(<1 \mathrm{~cm})$. Nonsocial behaviors were also represented in an overall exploration 478 score, which included cage exploration, rearing, digging, and self-grooming. Animals that had a 479 social interaction score of less than $5 \mathrm{~s}$ were excluded from further analysis.

480 Novel object exploration: The novel object test was performed exactly like the social interaction 481 assay. Instead of a young intruder, either a figurine or an equivalently sized Lego figure was 482 introduced to the mouse's homecage and total time spent investigating the object over 3 min was 483 quantified. Objects were thoroughly cleaned with $70 \%$ ethanol in between tests. Each experi484 mental mouse underwent two novel object investigation tests separated by 24 hours, with one 485 trial paired with optical stimulation and one with no stimulation, counterbalanced for order of light 486 stimulation and object.

487 Elevated plus maze assay: The elevated plus maze was made of grey plastic and consisted of 488 two open arms $(30 \times 5 \mathrm{~cm})$ and two enclosed arms $(30 \times 5 \times 30 \mathrm{~cm})$ extending from a central 489 platform $(5 \times 5 \mathrm{~cm})$. The maze was elevated $75 \mathrm{~cm}$ from the floor. Individual mice were connected 490 to the patch cable and allowed $2 \mathrm{~min}$ on the lid of the homecage for recovery from handling before 491 the 10 min session was initiated. Each session was divided into two 5 min epochs with only the 492 second epoch with light stimulation.

493 Open field test: Individual mice were connected to the patch cable and placed in the center of the 494 open field $(53 \times 53 \mathrm{~cm})$ at the start of the session. The open field test consisted of a 10 min session 
495 with two 5 min epochs in which the mouse was permitted to freely investigate the chamber. Stim-

496 ulation was given only during the second epoch.

497 Intracranial self-stimulation: A subset of mice was food restricted for 14-18 $\mathrm{h}$ prior to testing to 498 facilitate behavioral responding. Immediately before the start of the session, mice were connected 499 to a patch cord and placed in standard Med-Associates (St. Albans, VT, USA) operant chambers 500 equipped with an active and inactive nose-poke directly below two cue lights as well as audio 501 stimulus generators and video cameras. A 1 hour optical self-stimulation session began with the 502 onset of low volume white noise and illumination of both nose pokes. Each active nose poke 503 performed by the mouse resulted in optical stimulation of VTA cell bodies (either 8 or 90 pulses,

$50430 \mathrm{~Hz}, 5 \mathrm{~ms}$ pulse duration). Concurrently, the cue-light above the respective port was illuminated 505 and a distinct tone was played ( $1 \mathrm{kHz}$ and $1.5 \mathrm{kHz}$ counterbalanced), providing a visible and 506 auditory cue whenever a nosepoke occurred. Both active and inactive nosepoke time-stamp data 507 were recorded using Med-PC software and analyzed using custom-written MATLAB scripts 508 (Mathworks; Natick, MA).

\section{Laser delivery}

511 For optical manipulations during behavioral assays, the laser was first connected to a patch cord 512 with a pair of FC/PC connectors in each end (Doric; Québec, Canada). This patch cord was con513 nected through a fiber-optic rotary joint (Doric; Québec, Canada), which allows free rotation of the 514 fiber, with another patch cord with a side of FC/PC connector and a ferrule connection on the 515 other side that delivers the laser via a chronic optic fiber. Phasic activation of VTA cell bodies 516 consisted of $30 \mathrm{~Hz}$ bursts of eight $5 \mathrm{~ms}$ pulses of $473 \mathrm{~nm}$ light delivered every $5 \mathrm{sec}$ at a light 517 power output of 10-20 mW of blue light generated by a $100 \mathrm{~mW} 473 \mathrm{~nm}$ DPSS laser (OEM Laser 518 Systems; Draper, UT), delivered via an optical fiber. Inhibition of VTA cell bodies was performed 519 with $593 \mathrm{~nm}$ light delivered constantly at a light power output of $1 \mathrm{~mW}$ of yellow light, generated 520 by a $593 \mathrm{~nm}$ DPSS laser. Laser output was manipulated with a Master-8 pulse stimulator 521 (A.M.P.I.; Jerusalem, Israel). Onset of laser light was determined by behavioral hardware.

\section{Monitoring of estrous cycle}

524 After behavioral testing each day, a vaginal swab was collected using a cotton tipped swab (Pu525 ritan Medical Products Company; LLC Guilford, ME) wetted with saline (Byers et al., 2012). The 526 cells were spread on a microscope slide. Slides were air dried and stained with $500 \mu$ of Accustain 527 (Accustain, Sigma-Aldrich, St. Louis, MO) for approximately $45 \mathrm{~s}$. Slides were then rinsed with 528 water, coverslipped, and examined under a light microscope in order to determine the stage of 
529 the estrous cycle phase via vaginal cytology. For a subset of mice, unstained vaginal lavage

530 specimens were used to determine the estrous cycle (Marcondes et al., 2002).

\section{Pharmacology}

533 D1- (SCH-23390; 3.1 mM, Sigma-Aldrich, St. Louis, MO) and D2- (Raclopride; 2.89 mM, Sigma-

534 Aldrich, St. Louis, $\mathrm{MO})$ receptor antagonists were dissolved in sterile saline $(0.9 \% \mathrm{NaCl})$ freshly

535 each day. $\sim 10$ minutes before the start of the behavioral assay, $0.4 \mu$ of the DA receptor antag-

536 onist cocktail or vehicle (sterile saline) was infused into the NAc via dual internal infusion needles

537 connected to a $10 \mu \mathrm{l}$ microsyringe, inserted into the bilateral guide cannula. The flow rate was

538 kept at $100 \mathrm{nl}$ per min and regulated by a syringe pump (Harvard Apparatus, MA). Infusion nee-

539 dles were withdrawn 2 min after the infusion had finished. Testing of females took place over 4

540 consecutive days, each day a mouse only received one drug-light pairing counterbalanced for

541 order.

543 Immunohistochemistry and confocal microscopy

544 All mice were anesthetized with sodium pentobarbital and then transcardially perfused with ice545 cold phosphate-buffered saline (PBS) followed by 4\% paraformaldehyde (PFA) in PBS (pH 7.3). 546 Extracted brains were post-fixed in 4\% PFA overnight and then transferred to $30 \%$ sucrose in 547 PBS until equilibration. 50-60 $\mu$ m-thick coronal sections were sliced using a sliding microtome 548 (HM430: Thermo Fisher Scientific, Waltham, MA) and stored in PBS at $4^{\circ} \mathrm{C}$ until processed for 549 immunohistochemistry. Free-floating sections were blocked for $1 \mathrm{hr}$ at room temperature in Triton $550 \quad 0.3 \% / P B S$ and 3\% normal donkey serum. Primary antibody (chicken anti-TH 1:1000; AB39702, 551 Millipore, Temecula, CA) was incubated for $24 \mathrm{hrs}$ at $4^{\circ} \mathrm{C}$ in Triton $0.3 \% / \mathrm{PBS}$ and $3 \%$ normal 552 donkey serum. Sections were then washed 4 times for 10 min each with PBS and incubated with 553 secondary antibody (Cy3 or Alexa-647 donkey anti-chicken 1:1000; 703-605-155 Jackson Immu554 noResearch Laboratories, Inc., West Grove, PA) and a DNA specific fluorescent probe (DAPI: 555 4',6-Diamidino-2-Phenylindole, 1:50,000) for $2 \mathrm{hrs}$ at room temperature. Sections were washed 556 again for $4 \times 10$ min with PBS followed by mounting on microscope slides with PVA-DABCO. 557 Fluorescence images were acquired using an Olympus FV1000 confocal laser scanning micro558 scope using a 10x/0.40 NA or a 40x/1.30 NA oil-immersion objective. Mice without viral expres559 sion or mistargeted fiber placements were excluded from further analysis.

\section{Statistics}


562 Sample sizes are based on past experience and similar to those presented in related literature.

563 There was no predetermined calculation. Statistical analyses were performed using commercial

564 software (GraphPad Prism, GraphPad Software, Inc, La Jolla, CA; MATLAB, Mathworks, Natick,

565 MA or SPSS, IBM, Armonk, NY). Group comparisons were made using repeated measures anal-

566 ysis of variance (ANOVA), including one-, two-, or three-way ANOVAs as indicated. Post-hoc

567 tests were corrected for multiple comparisons using Dunnett's post-hoc tests to compare means

568 from experimental stress exposed groups (recent or remote) to non-stressed controls, or using

569 Sidak's post-hoc tests when appropriate. P-values reported reflect values corrected for the multi-

570 ple comparisons using these methods. Single variable comparisons were detected with two-tailed

571 paired or unpaired Student t-tests. Correlations were calculated using Pearson correlations. A

572 Grubb's test was performed on individual data sets to identify outliers. Significance thresholds are

573 noted as ${ }^{+} p \leq 0.1,{ }^{*} p \leq 0.05,{ }^{* *} p \leq 0.01,{ }^{* * *} p \leq 0.001$. All data are shown as mean \pm SEM. 


\section{Acknowledgments}

575 We thank P. Namburi for sharing custom MATLAB scripts, Erik Douma and the entire Tye

576 Laboratory for helpful support and discussion. We also thank Jordan T. Yorgason (Oregon Health

577 and Science University) for providing custom scripts for fast-scan cyclic voltammetry analyses.

578 K.M.T. is a Picower Institute Faculty Member and New York Stem Cell Foundation - Robertson

579 Investigator and acknowledges funding from the JPB Foundation, PIIF, PNDRF, Whitehall

580 Foundation, Klingenstein Foundation, NARSAD Young Investigator Award, Alfred P Sloan

581 Foundation, NIH R01-MH102441-01 (NIMH) and NIH Director's New Investigator Award DP2-

582 DK-102256-01 (NIDDK). R.W. acknowledges funding from the Simons Center for the Social Brain,

583 the Netherlands Organization for Scientific Research (NWO) RUBICON fellowship program, and

584 a NARSAD Young Investigator Grant from the Brain \& Behavior Research Foundation. C.M.V.W.

585 was supported by the NSF Graduate Research Fellowship (NSF GRFP) and the Integrative

586 Neuronal Systems Training Fellowship (T32 GM007484). A.S.Y., S.S., and K.M.F. were funded

587 by the Undergraduate Research Opportunities Program at MIT. E.Y.K. is supported by the

588 Collaborative Clinical Neuroscience Fellowship at the Picower Institute for Learning and Memory.

590 Author contributions

591 R.W. and K.M.T. conceived and supervised the study. R.W., C.M.V.W., and K.M.T. contributed 592 to experimental design. R.W., A.S.Y., E.H.S.S., J.P.H.V., S.S., E.M.I., and K.M.F. executed and 593 analyzed behavioral experiments. R.W., C.M.V.W., and C.A.S. conducted and analyzed FSCV 594 recordings. R.W., A.S.Y., E.H.S.S., and C.A.S. performed stereotaxic surgeries. R.W., C.M.V.W., 595 A.S.Y., E.H.S.S., J.P.H.V., S.S., E.M.I., K.M.F. performed immunohistochemistry. C.P.W. and 596 E.Y.K. contributed to data analysis. R.W., C.M.V.W., E.Y.K. and K.M.T. wrote the paper, all 597 authors contributed to editing the paper. The authors declare no competing financial interest. 
Wichmann, Vander Weele, Yosafat et al. Figure 1

A $\quad \square$ Stress Exposure $\quad \square$ Experiments

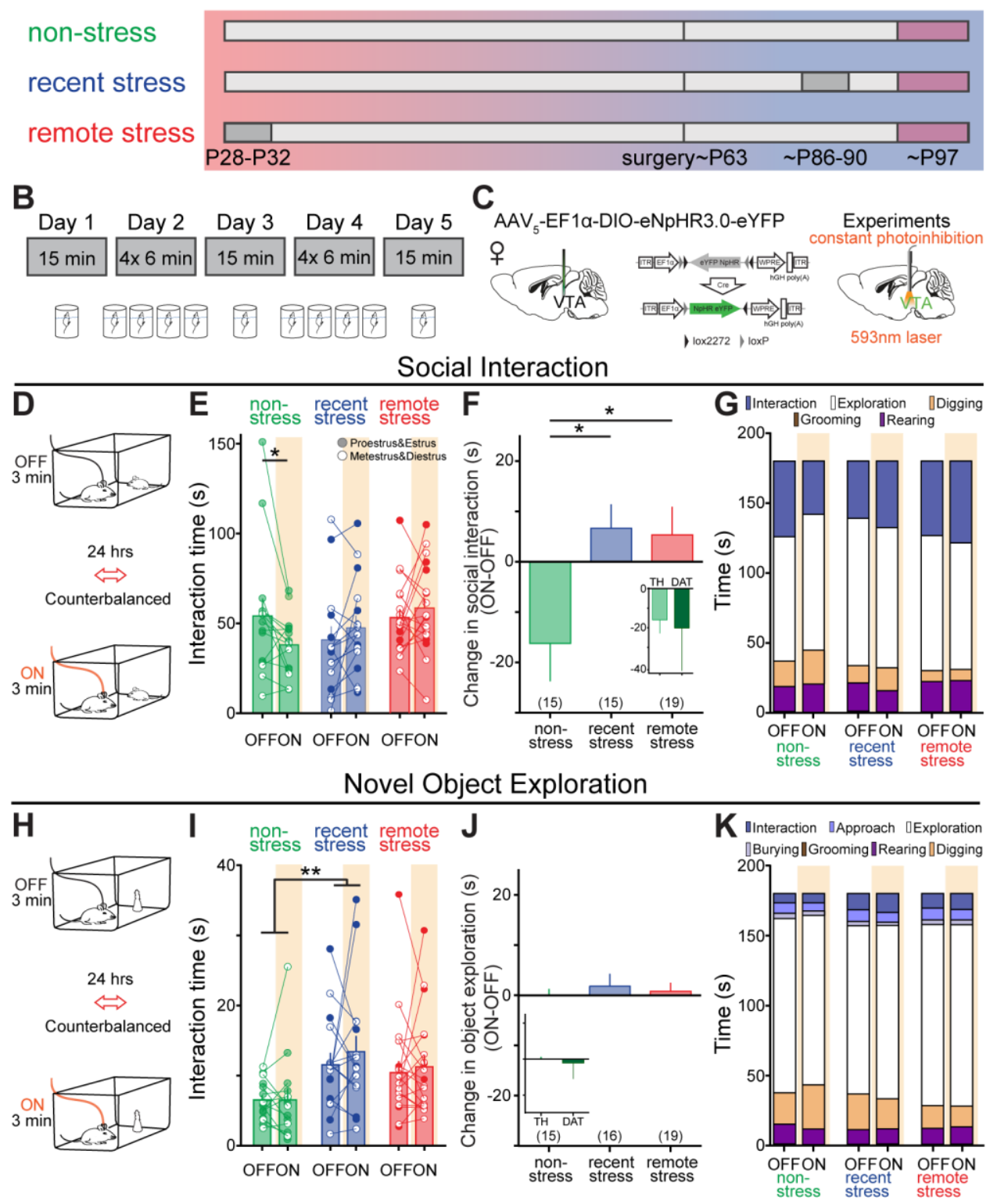

Figure 1. Stress attenuates the effects of VTA DA neuron inhibition on social interaction.

(A) Experimental timeline for mice in each exposure group. (B) Schematic of stress exposure

602 paradigm, corresponding to grey boxes in (A). (C) VTA DA neurons were transduced with AAV $_{5^{-}}$

603 EF1 $\alpha$-DIO-eNpHR3.0-eYFP and photoinhibited with constant yellow light (593 nm) delivered via

604 an optical fiber implanted above the VTA. (D) Schematic of social interaction paradigm. (E)

605 Photoinhibition of VTA DA neurons affected social interaction differently depending on prior stress

606 exposure. There was a significant interaction of photostimulation and treatment in the social

607 interaction assay (Two-way repeated measures ANOVA, main effect of stimulation: $F_{1,46}=0.159$, 
$608 \mathrm{p}=0.692$; main effect of stress exposure: $F_{2,46}=1.278, p=0.288$; light-by-stress exposure

609 interaction: $F_{2,46}=4.581, p=0.015$; Sidak's post-hoc test; $\left.{ }^{*} p=0.033\right)$. ( $F$ ) Compared to its effects in

610 non-stressed mice, photoinhibition of VTA DA neurons was significantly less likely to decrease

611 social interaction (one-way ANOVA, $F_{2,46}=4.581, p=0.015$ ) in both recently (Dunnett's post-hoc

612 test; $\left.{ }^{*} p=0.022\right)$ and remotely $\left({ }^{*} p=0.023\right)$ stressed mice. Inset: There was no difference in the effect

613 of photostimulation on social interaction behaviors between non-stressed TH::Cre $(n=15)$ and

614 DAT::Cre $(n=5)$ mice (unpaired t-test, two-tailed; $t_{18}=0.311, p=0.759$ ). (G) Breakdown of mean

615 time spent engaging in social interaction, grooming, rearing, digging and cage exploration

616 behaviors during the social interaction task, for $3 \mathrm{~min}$ light-ON and light-OFF epochs grouped by

617 stress exposure. (H) Schematic of object exploration paradigm. (I) Novel object exploration was

618 not affected by photoinhibition (Two-way repeated measures ANOVA, main effect of light:

$619 F_{1,47}=0.68, p=0.413$; light-by-stress exposure interaction: $F_{2,47}=0.22, p=0.801$ ), though stress

620 exposure increased novel object exploration independent of VTA DA neuron photoinhibition (main

621 effect of stress exposure: $F_{2,47}=4.5, p=0.016$ ) after recent stress exposure (Sidak's post-hoc test,

$\left.622{ }^{* *} \mathrm{p}=0.017\right)$. (J) In contrast to social interaction, the effects of photoinhibition on novel object

623 exploration did not differ between the stress exposure groups (One-way ANOVA, $F_{2,47}=0.223$,

$624 \mathrm{p}=0.801)$. Inset: There was no difference in the effect of photoinhibition on social interaction

625 behaviors between non-stressed TH::Cre $(n=15)$ and DAT::Cre $(n=5)$ mice (unpaired t-test, two-

626 tailed; $t_{18}=0.718, p=0.482$ ). (K) Breakdown of mean time spent engaging in various behaviors

627 during the novel object exploration task, including novel object exploration, for 3 min light-ON and

628 light-OFF epochs, grouped by prior stress exposure. Numbers in brackets indicate number of

629 mice per group. Error bars indicate \pm SEM.

630

631

632

633 
Wichmann, Vander Weele, Yosafat et al. Figure 2

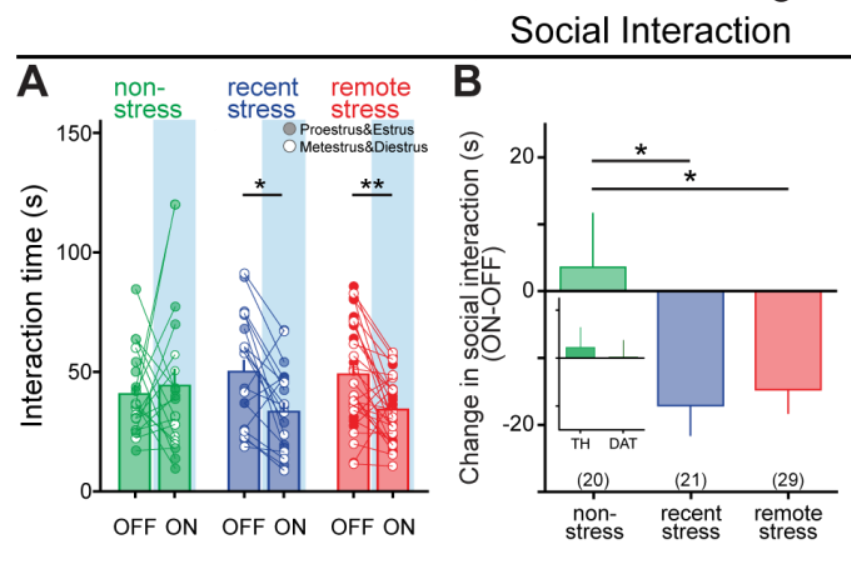

Novel Object Exploration
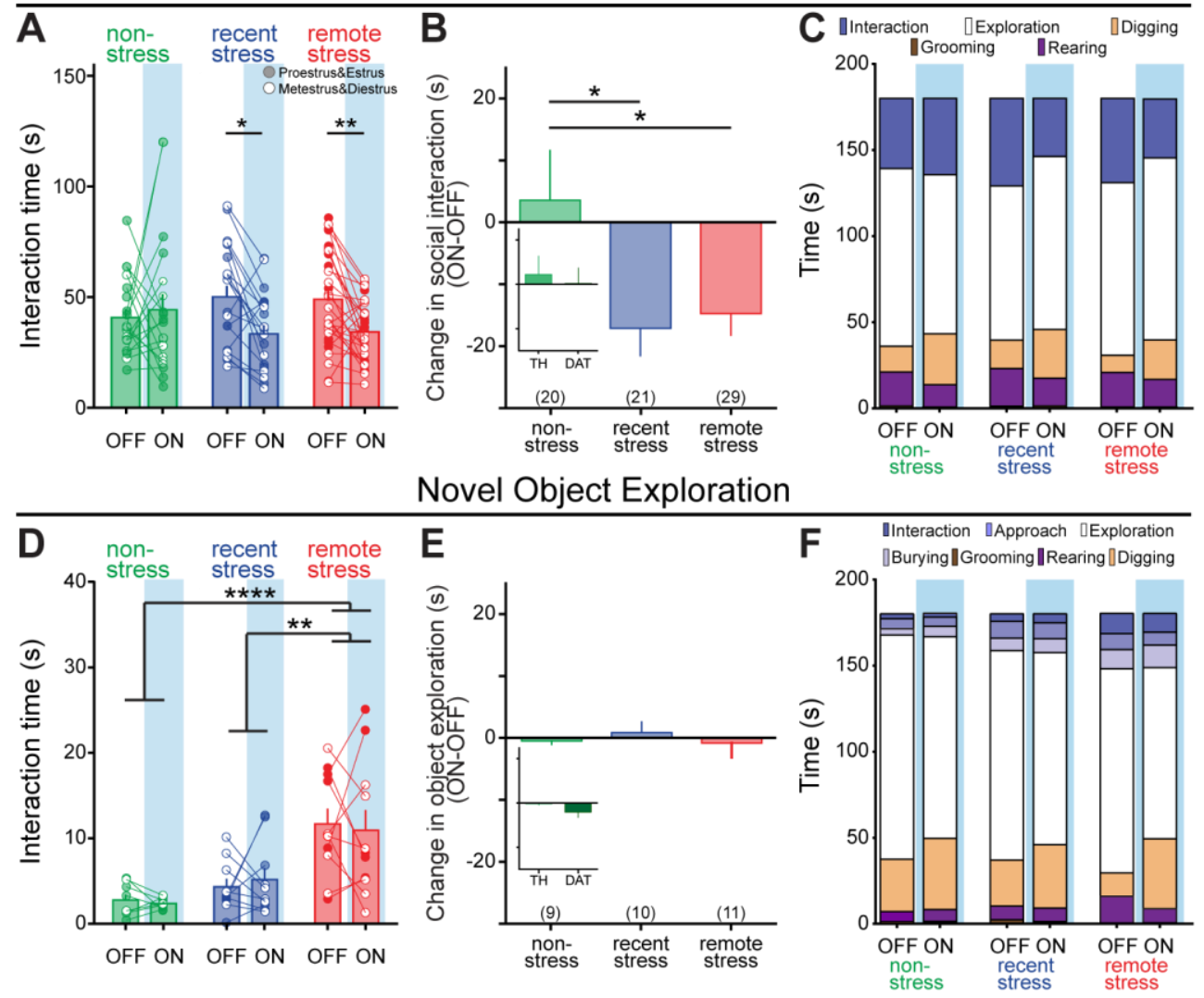

Figure 2. Stress turns phasic VTA DA neuron activation into an anti-social signal.

(A) Photoactivation of VTA DA neurons induced a significant effect stimulation and a treatment by stimulation interaction effect in the social interaction assay (Two-way repeated measures ANOVA, main effect of stimulation: $F_{1,67}=8.991, p=0.004$; main effect of stress exposure: $F_{2,67}=0.02, p=0.981$; light-by-stress exposure interaction: $F_{2,67}=4.041, p=0.022$ ). Both recent

640 (Sidak's post-hoc test ${ }^{*} \mathrm{p}=0.012$ ) and remote $\left({ }^{* *} \mathrm{p}=0.008\right)$ stress mice spend less time interacting 641 during the light stimulation (ON) trial compared to the unstimulated (OFF) trial. (B) Compared to

642 its effects in non-stressed controls, photoactivation of VTA DA neurons was more likely to 643 decrease social interaction in both recently (Dunnett's post-hoc test, ${ }^{*} \mathrm{p}=0.025$ ) and remotely

$644\left({ }^{*} p=0.03\right)$ stressed mice. Inset: There was no difference in the effect of photostimulation on social 645 interaction behaviors between non-stressed TH::Cre $(n=20)$ and DAT::Cre $(n=8)$ mice (unpaired 646 t-test, two-tailed; $\left.t_{25}=0.289, p=0.775\right)$. (C) Breakdown of mean time spent engaging in social 647 interaction, grooming, rearing, digging and cage exploration behaviors during the social 648 interaction task for 3 min light-ON and light-OFF epochs grouped by stress exposure. (D) In 649 contrast to social interaction, novel object exploration was not affected by photoactivation or by 
650 the interaction between light and stress exposure (Two-way repeated measures ANOVA, main

651 effect of light: $F_{1,27}=0.01, p=0.921$; interaction of light-by-stress exposure, $F_{2,27}=0.22, p=0.802$ ),

652 though remote stress exposure significantly increased novel object exploration (main stress

653 exposure effect: $F_{2,27}=14, p<0.0001$ ) compared to both non-stressed controls (Sidak's post-hoc

654 test; $\left.{ }^{* \star \star} \mathrm{p}<0.0001\right)$ and recently stressed mice $\left({ }^{\star *} \mathrm{p}=0.002\right)$. (E) The effects of photostimulation on

655 novel object exploration did not differ between the stress exposure groups (one-way ANOVA;

$\left.656 F_{2,27}=0.222, p=0.802\right)$. Inset: There was no difference in the effect of photostimulation on novel

657 object exploration between non-stressed TH::Cre $(n=9)$ and DAT::Cre $(n=8)$ mice (unpaired t-test,

658 two-tailed; $\left.t_{15}=1.572, p=0.137\right)$. $(F)$ Breakdown of mean time spent engaging in various behaviors

659 during the novel object exploration task for 3 min light-ON and light-OFF epochs, grouped by prior

660 stress exposure. Numbers in brackets indicate number of mice per group. Error bars indicate

$661 \pm$ ISEM.

662

663

664

665

666

667

668

669

670

671

672

673

674

675

676

677

678 
Wichmann, Vander Weele, Yosafat et al. Figure 3
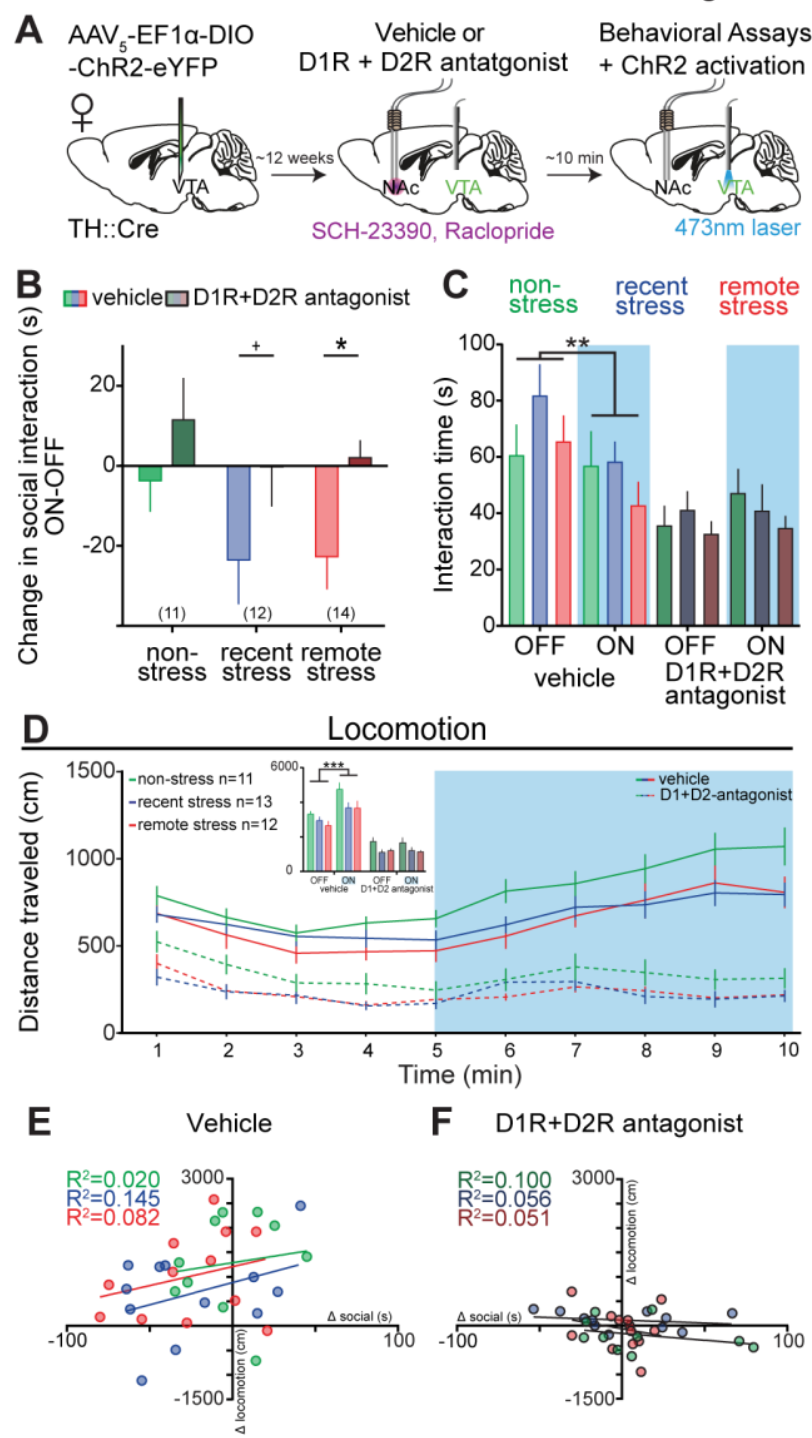

Figure 3. Light-induced behavioral effects in stressed mice are blocked by intra-NAc DAreceptor blockade.

682 (A) To test the role of dopamine in the effects of VTA photostimulation on social interaction, 683 dopamine receptor antagonists (D1R: SCH23390, D2R: Raclopride) or vehicle (saline) were 684 bilaterally infused into the NAc approximately 10 minutes prior to social interaction assays. (B) 685 The effects of photoactivation were significantly different in the presence of dopaminergic

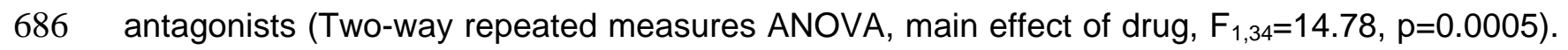

687 Dopaminergic antagonists attenuated light-induced decreases in social interaction, measured as 688 difference scores (ON-OFF), in recently (Sidak's post-hoc test, ${ }^{+} p=0.06$ ) and remotely $\left({ }^{*} p=0.026\right)$ 689 stressed mice. (C) The effects of photostimulation differed based on infusion of dopaminergic 690 antagonists (Three-way repeated measures ANOVA: main effect of drugs: $F_{1,34}=31.916$, 
$691 p=0.0005$; drugs-by-photostimulation interaction $F_{1,34}=14.782, p=0.001$ ). Photostimulation of VTA

692 DA neurons significantly decreased social behavior after infusion of vehicle $\left({ }^{* *} \mathrm{p}=0.003\right)$, but not

693 after infusion of dopaminergic antagonists $(p=0.362)$. (D) Photostimulation as well as drug

694 administration effected open-field locomotion. A three-way repeated measures ANOVA,

695 comparing 5 min epochs, revealed a main effect of drug treatment $\left(F_{1,30}=117.05, p=0.0005\right)$,

696 stress exposure $\left(F_{2,30}=4.067, p=0.027\right)$, and light stimulation $\left(F_{1,30}=25.952, p=0.0005\right)$ as well as

697 a drug-by-light interaction $\left(F_{1,30}=40.780, p=0.0005\right)$, but no other interactions (drug-by-stress

698 interaction: $F_{2,30}=0.284, p=0.755$; light-by-stress interaction: $F_{2,30}=0.278, p=0.759$; drug-by-light-

699 by-stress interaction: $\left.F_{2,30}=1.972, p=0.157\right)$. Upon pairwise comparison we observed that

700 photostimulation increased locomotion in all vehicle-treated groups (Sidak's post-hoc test;

$\left.701^{* * *} p=0.001\right)$ however, no difference was detected in the drug-treated groups $(p=0.999)$. (E-F)

702 Photostimulation effects on social interaction ( $\Delta$ social, ON-OFF) did not correlate with

703 photostimulation effects on locomotion ( $\Delta$ locomotion, ON-OFF) during neither $(E)$ vehicle

704 treatment (Pearson's correlation: non-stressed: $r=0.142, p=0.697$; recently stressed: $r=0.381$,

$705 p=0.221$; remotely stressed: $r=0.287, p=0.366)$ nor $(F)$ drug treatment (Pearson's correlation: non-

706 stressed: $r=-0.317, p=0.373$; recently stressed: $r=-0.236, p=0.484$; remotely stressed: $r=-0.227$,

$707 \mathrm{p}=0.456)$. Numbers in brackets indicate number of mice per group. Error bars indicate \pm SEM. 
bioRxiv preprint doi: https://doi.org/10.1101/168492; this version posted July 27, 2017. The copyright holder for this preprint (which was not certified by peer review) is the author/funder, who has granted bioRxiv a license to display the preprint in perpetuity. It is made available under aCC-BY 4.0 International license.

Wichmann, Vander Weele, Yosafat et al.,Figure 4

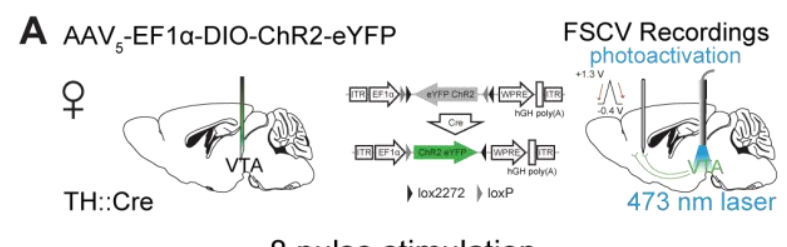

8 pulse stimulation

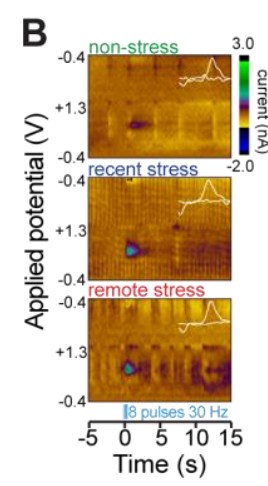

\section{C}

D
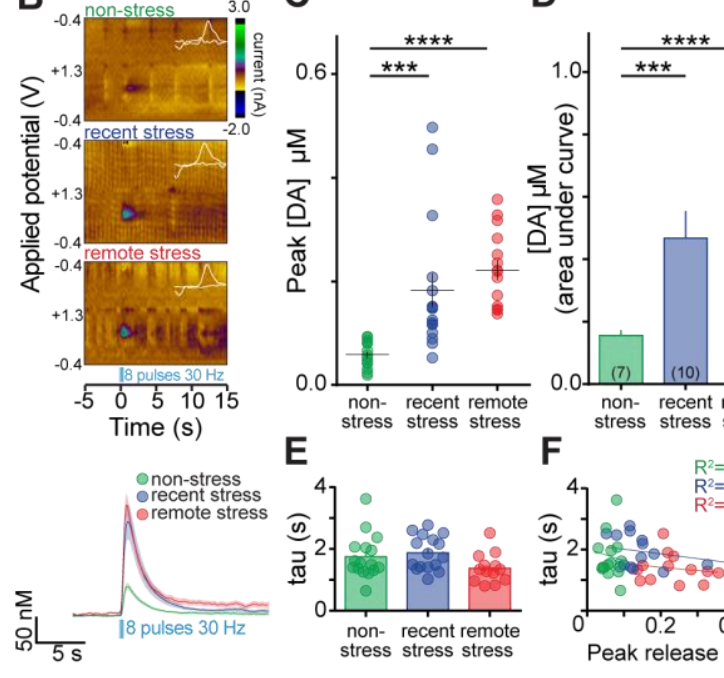

E
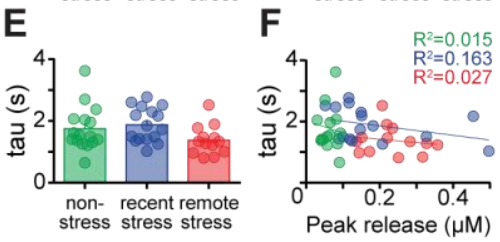

90 pulse stimulation

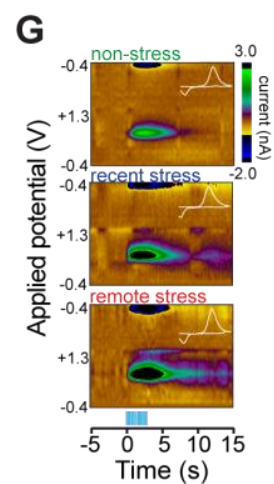

H I
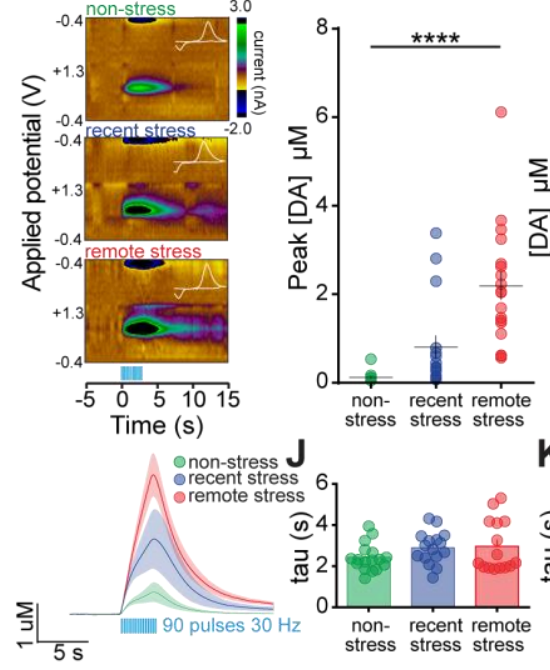

I
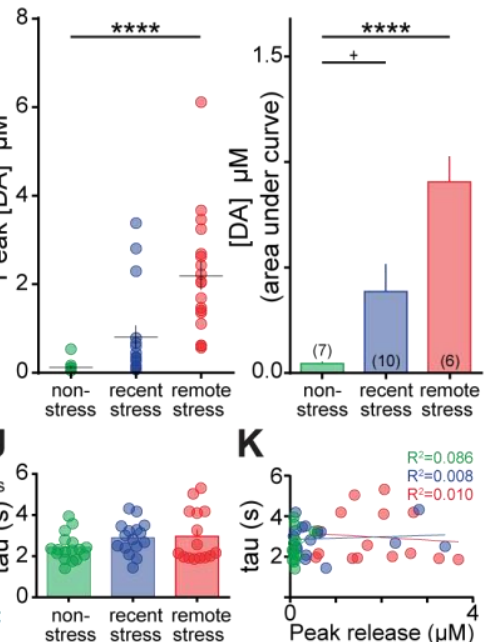

K

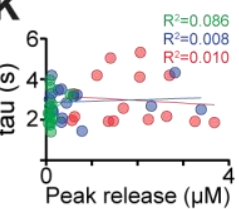

L 8 pulse stimulation
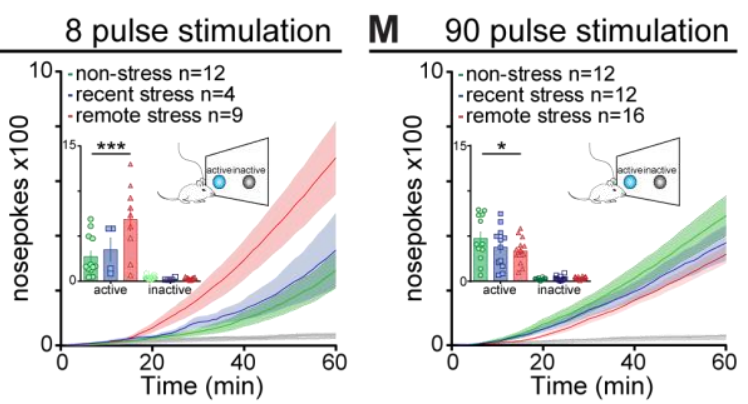


\section{Figure 4. Stress increases optically-induced DA-release in the NAc}

711 (A) VTA DA neurons in TH::Cre female mice were transfected with AAV 5 -EF1 $\alpha$-DIO-ChR2-eYFP

712 and photostimulated with blue light $(473 \mathrm{~nm})$ delivered via optical fibers implanted above the VTA.

713 Anesthetized fast-scan cyclic voltammetry (FSCV) recordings were performed in the NAc while

714 DA release was evoked by photostimulation of VTA DA neurons in non-stressed ( $\mathrm{n}=7$ mice, $n=16$

715 recording sites), recently stressed ( $n=10$ mice, $n=16$ recording sites), and remotely stressed $(n=5$,

$716 \mathrm{n}=15$ recording sites) mice using blue light (473 nm, $30 \mathrm{~Hz}, 8$ pulses, $20 \mathrm{~mW}, 5 \mathrm{~ms}$ pulse duration)

717 delivered via an optical fiber to the VTA. (B) Representative color plots suggest that VTA

718 photostimulation increased current at the oxidation potential for DA in recently and remotely

719 stressed mice relative to non-stressed mice. Differences between recently and remotely stressed

720 mice and non-stressed mice became apparent after signal conversion from evoked current to

721 changes in extracellular DA concentration ([DA]) (lower panel; mean \pm SEM). (C) The peak [DA]

722 evoked by optical activation of VTA DA neurons differed based on stress exposure (One-way

723 ANOVA, $F_{2,44}=14.66$, $p<0.0001$ ), with significantly greater peak DA concentrations in recently

724 (Dunnett's post-hoc test; $\left.{ }^{* * *} \mathrm{p}=0.0005\right)$ and remotely $\left({ }^{* * *} \mathrm{p}<0.0001\right)$ stressed mice compared to

725 non-stressed mice. (D) Quantification of [DA] as area under the curve revealed that light-evoked

726 DA release also differed based on stress exposure (one-way ANOVA, $F_{2,44}=14.37, p<0.0001$ ) and

727 was enhanced in recently (Dunnett's post-hoc test, ${ }^{* * *} \mathrm{p}=0.0007$ ) and remotely stressed

$728 \quad\left({ }^{* * *} \mathrm{p}<0.0001\right)$ mice. $(\mathrm{E})$ There were no significant differences in the rate of decay, measured as

729 tau, between groups (one-way ANOVA, $F_{2,42}=2.724, p=0.077$ ). ( $F$ ) Analysis of the relationship

730 between tau and peak release for different stress exposures (Pearson's correlation; non-stress:

$731 r=-0.122, p=0.665$; recent stress: $r=-0.3661, p=0.163$; remote stress: $r=-0.165, p=0.591$ ) showed

732 no relationship between tau and release. (G) Representative color plots illustrating VTA

733 photostimulation increased current at the oxidation potential for DA in recently and remotely

734 stressed mice relative to non-stressed controls using a higher intensity stimulation paradigm (473

$735 \mathrm{~nm}, 30 \mathrm{~Hz}, 90$ pulses, $20 \mathrm{~mW}, 5 \mathrm{~ms}$ pulse duration). Differences between recently ( $\mathrm{n}=10$ mice,

$736 \mathrm{n}=16$ recording sites) and remotely stressed ( $\mathrm{n}=6$ mice, $\mathrm{n}=18$ recording sites) mice and non-

737 stressed controls ( $n=6$ mice, $n=14$ recording sites) were also apparent in the average converted,

738 evoked concentrations of DA (lower panel; mean \pm SEM). (H) The peak extracellular DA

739 concentration ([DA]) evoked by optical activation of VTA DA neurons differed based on stress

740 exposure (one-way ANOVA, $F_{2,45}=16.82, p<0.0001$ ) with significantly greater peak [DA] in

741 remotely stressed mice compared to non-stressed controls (Dunnett's post-hoc test;

$\left.742^{* * * *} p<0.0001\right)$. (I) Quantification of [DA] as area under the curve revealed that light-evoked DA

743 release differed based on stress exposure (one-way ANOVA, $F_{2,45}=15.24, p<0.0001$ ) and was 
744 enhanced in recently (Dunnett's post-hoc test, ${ }^{+} p=0.077$ ) and remotely stressed mice

$745 \quad\left({ }^{* * *} \mathrm{p}<0.0001\right)$ compared to non-stress controls. $(\mathrm{J})$ There were no significant differences in the

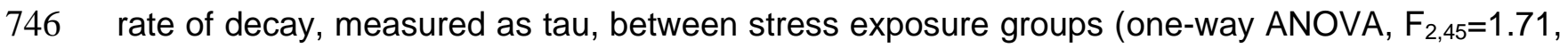
$747 \mathrm{p}=0.192)$. (K) There were no statistically significant correlations of tau and peak release in any of 748 the groups (Pearson's correlation; non-stress: $r=0.294, p=0.308$; recent stress: $r=0.091, p=0.737$; 749 remote stress: $r=-0.100, p=0.723$ ). (L) All groups showed robust intracranial self-stimulation for 750 photostimulation (8 pulses, $30 \mathrm{~Hz}, 20 \mathrm{~mW}, 5 \mathrm{~ms}$ pulse) of VTA DA neurons. Significantly more nose 751 pokes were performed into the active versus the inactive nose-poke port. Performance differed 752 based on prior stress exposure (Two-way repeated measures ANOVA; main effect of 753 active/inactive nose-poke port: $F_{1,22}=34.62$; $p<0.0001$; effect of stress exposure: $F_{2,22}=4.654$, $754 \mathrm{p}=0.021$ and interaction of nose poke-by-stress exposure: $F_{2,22}=4.958, p=0.017$ ) with the remote 755 stress group performing more active nose-pokes compared to the non-stress group (Dunnett's 756 post-hoc test, ${ }^{* *} \mathrm{p}=0.0002$ ). (M) All groups additionally showed robust intracranial self-stimulation 757 for higher intensity photostimulation (90 pulses, $30 \mathrm{~Hz}, 20 \mathrm{~mW}, 5 \mathrm{~ms}$ pulse) of VTA DA neurons. 758 Significantly more nose pokes were performed into the active versus the inactive nose-poke port. 759 Performance differed based on prior stress exposure (Two-way repeated measures ANOVA; 760 main effect of active/inactive nose-poke port: $F_{1,37}=127.4 ; p<0.0001$; effect of stress exposure: $761 F_{2,37}=1.397, p=0.26$ and interaction of nose poke-by-stress exposure: $F_{2,37}=1.99, p=0.151$ ) with 762 the remote stress group performing less active nose-pokes compared to the non-stress group 763 (Dunnett's post-hoc test, $\left.{ }^{*} p=0.025\right)$. Color plot insets: cyclic voltammograms (CVs). Numbers in 764 brackets indicate number of mice per group. Error bars indicate \pm SEM. 


\section{Wichmann, Vander Weele, Yosafat et al.,Figure 5}
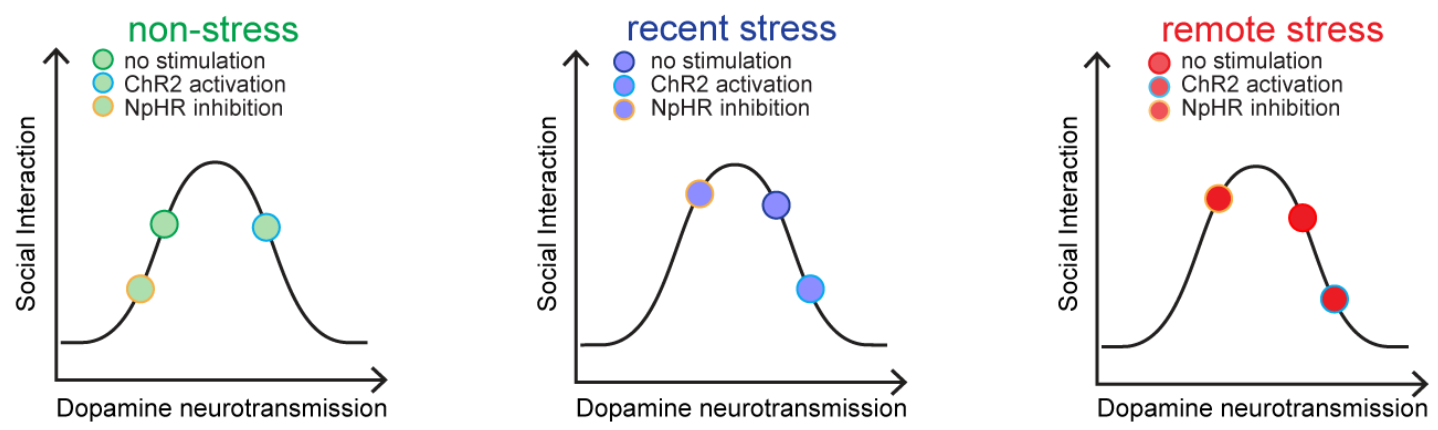

768 Figure 5. Proposed model of interaction between stress, dopamine and social interaction.

769 An optimal level of DA neuron activity is necessary and promotes social interaction. However,

770 sub- or supra-optimal levels of DA neurotransmission, induced by photoinhibition (orange-

771 rimmed circles) or photostimulation (blue-rimmed circles) in this study, causes a reduction in

772 social interaction.

773

774

775

776

777

778

779

780

781

782

783 
bioRxiv preprint doi: https://doi.org/10.1101/168492; this version posted July 27,2017. The copyright holder for this preprint (which was not certified by peer review) is the author/funder, who has granted bioRxiv a license to display the preprint in perpetuity. It is made available under aCC-BY 4.0 International license.

Figure 1 - figure supplement 1
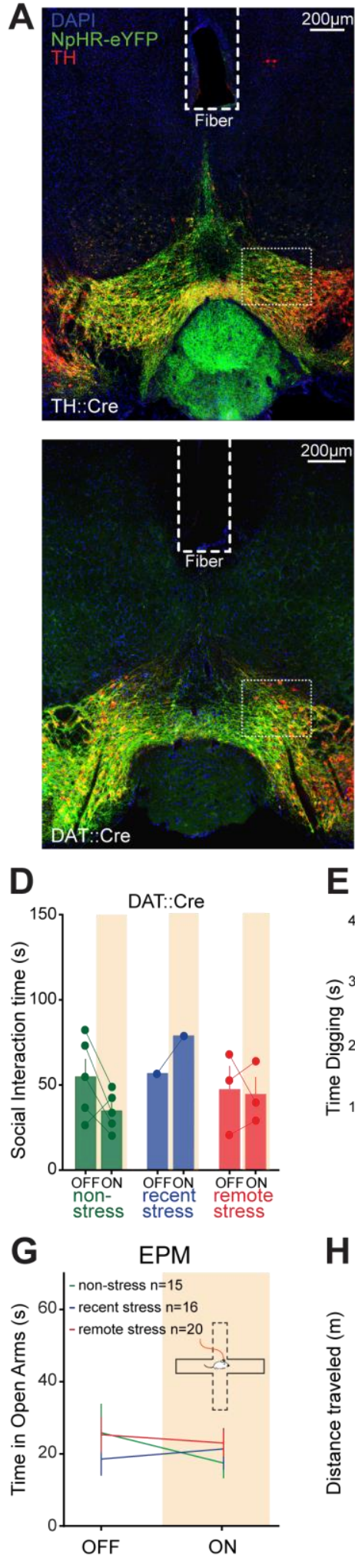

E

H
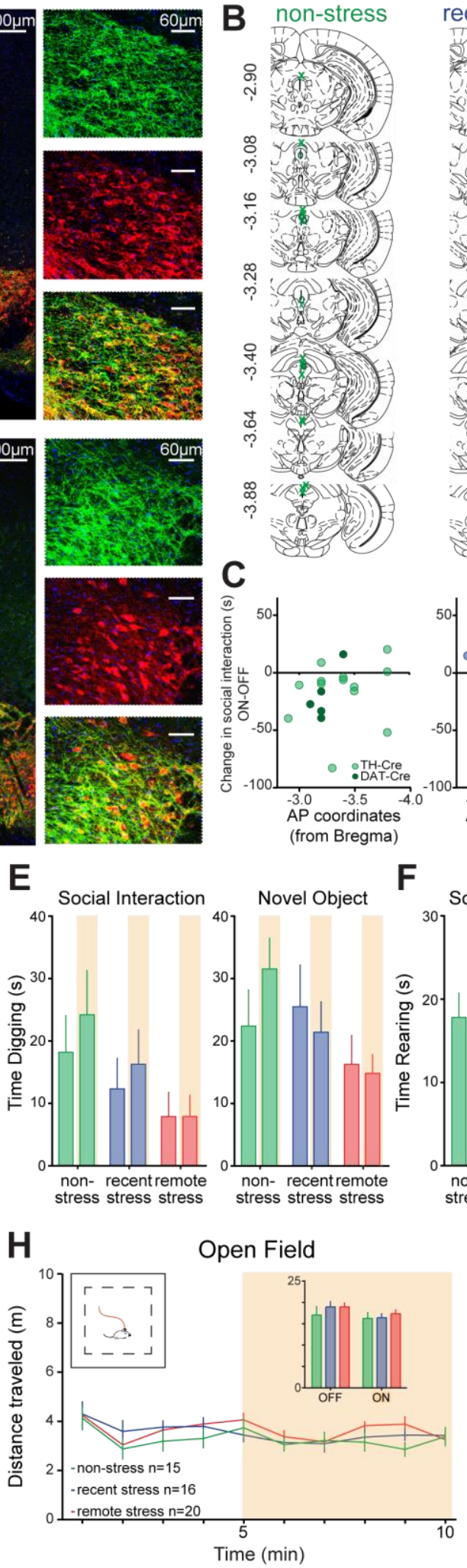

$F$
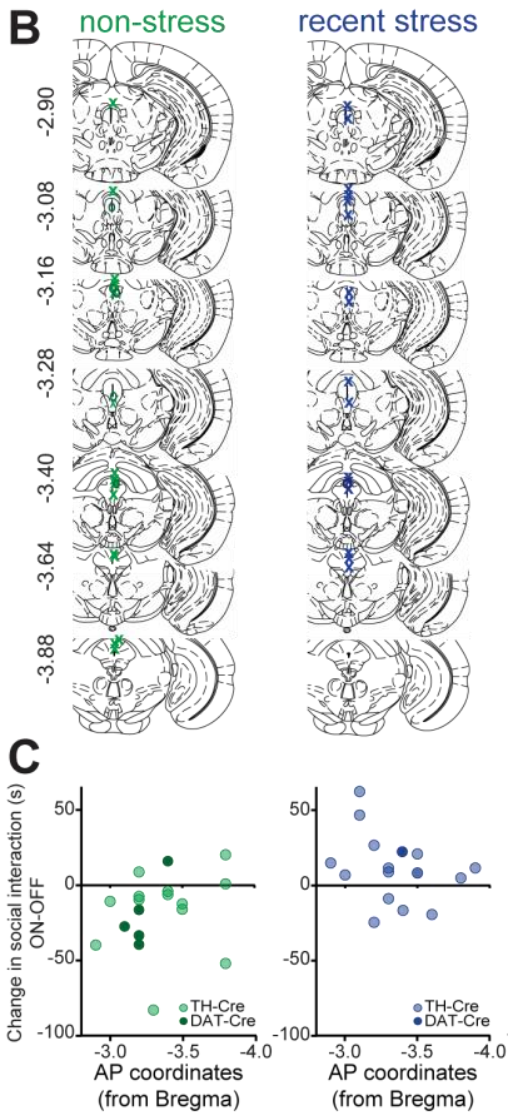

remote stress
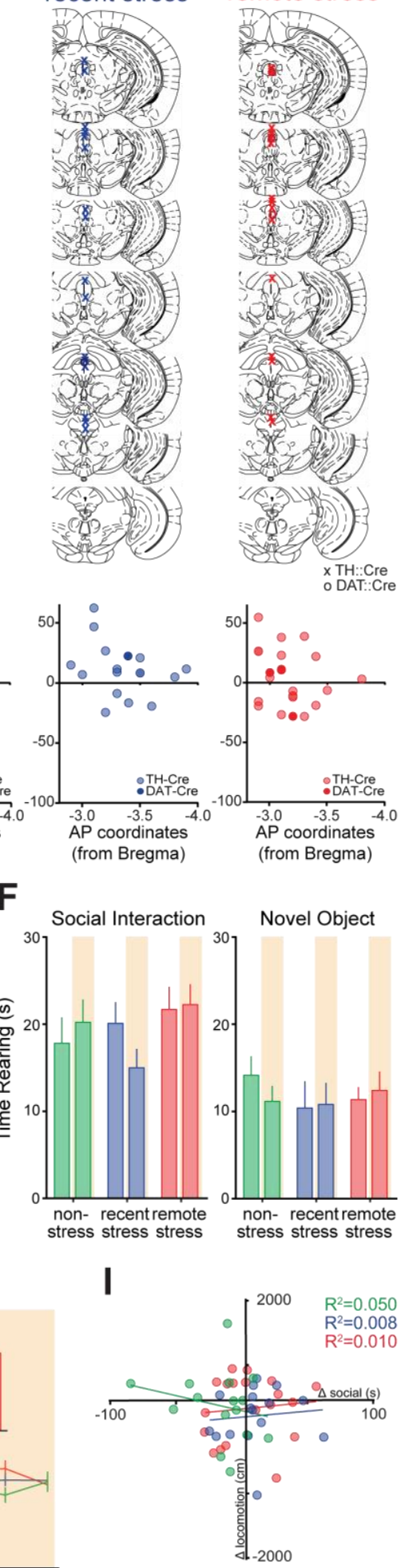
Figure 1 - figure supplement 1

786 (A) Confocal images of a $50 \mu \mathrm{m}$ thick coronal section containing the VTA of a TH::Cre female

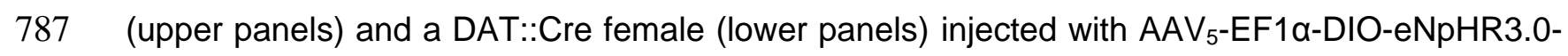
788 eYFP (left). Thinly dotted white square: localization of the magnified images (40x; DAPI in blue; eNpHR3.0-eYFP in green; TH in red). (B) Histologically verified optical fiber placements for all subjects included in photoinhibition studies. Symbols represent termination of fiber tract for each group. (C) Scatter-plot of anterior-posterior (AP) fiber placement, measured from bregma, vs. social interaction difference scores (ON-OFF) in all mice included in this experiment. There was no correlation between AP of fiber placement and social interaction in any of the experimental groups. (D) Effect of photoinhibition of VTA DA neurons in DAT::Cre mice in the social interaction assay. (E) There was no effect of light stimulation, stress exposure, or an interaction effect on the time spend digging during either the social interaction (Two-way repeated measures ANOVA, main effect of light: $F_{1,46}=1.110, p=0.722$; main effect of stress exposure: $F_{2,46}=2.396, p=0.102$; light-by-stress exposure interaction: $F_{2,46}=0.328, p=0.722$ ) or the novel object exploration task (Two-way repeated measures ANOVA, main effect of light: $F_{1,47}=0.181, p=0.673$; main effect of stress exposure: $F_{2,47}=1.813, p=0.174$; light-by-stress exposure interaction: $F_{2,47}=1.880$, $\mathrm{p}=0.164)$. (F) There was no effect of light stimulation, stress exposure, or an interaction effect on the time spend rearing during either the social interaction (Two-way repeated measures ANOVA, main effect of light: $F_{1,46}=0.189, p=0.666$; main effect of stress exposure: $F_{2,46}=1.046, p=0.360$; light-by-stress exposure interaction: $F_{2,46}=1.838, p=0.171$ ) or the novel object exploration task (Two-way repeated measures ANOVA, main effect of light: $F_{1,47}=0.083, p=0.774$; main effect of stress exposure: $F_{2,47}=0.401, p=0.672$; light-by-stress exposure interaction: $F_{2,47}=0.469$, $p=0.629)$.(G) No significant effect of photoinhibition or stress exposure was observed on open arm exploration in the elevated plus maze assay (Two-way repeated measures ANOVA, main

809 effect of light: $F_{1,48}=0.495, p=0.485$; main effect of stress exposure: $F_{2,48}=0.279, p=0.758$; light-

810 by-stress exposure interaction: $\left.F_{2,48}=0.686, p=0.509\right)$. $(H)$ Photoinhibition of VTA DA neurons did 811 not produce a significant light-by-stress exposure interaction in open-field locomotion (Inset; two812 way repeated measures ANOVA comparing summed 0-5 min light-OFF vs. 5-10 min light-ON

813 locomotion by stress exposure interaction, $F_{2,48}=0.41, p=0.664$ ). (I) Photoinhibition effects on

814 social interaction ( $\triangle$ social, ON-OFF) did not correlate with photoinhibition effects on locomotion 815 ( $\triangle$ locomotion, ON-OFF) in any of the stress exposure groups (Pearson's correlation: non816 stressed: $r=-0.224, p=0.423$; recently stressed: $r=0.091, p=0.738$; remotely stressed: $r=0.100$, $817 \mathrm{p}=0.684)$. 
bioRxiv preprint doi: https://doi.org/10.1101/168492; this version posted July 27 2017. The copyright holder for this preprint (which was not certified by peer review) is the author/funder, who has granted bioRxiv a license to display the preprint in perpetuity. It is made available under aCC-BY 4.0 International license.

Figure 2 - figure supplement 1
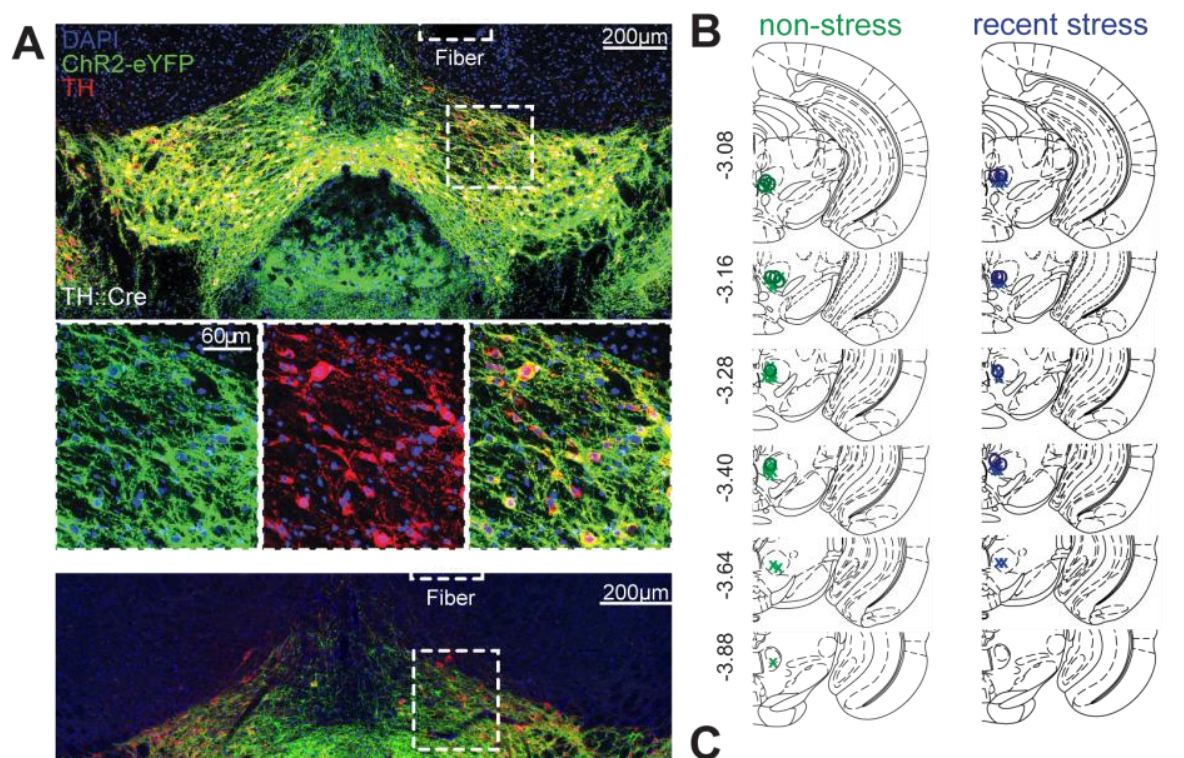

remote stress
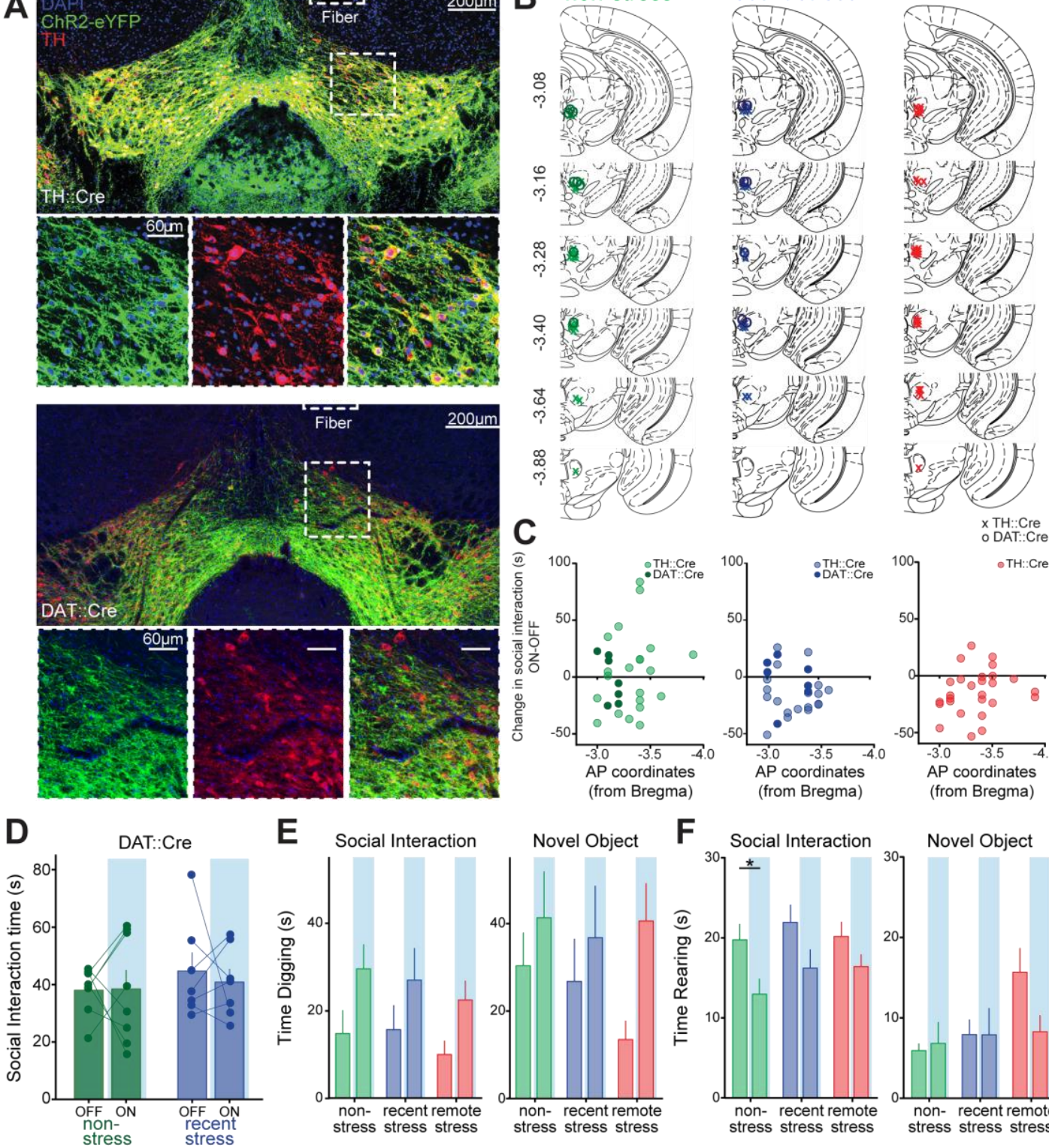

E Social Interaction

Novel Object $\quad \mathbf{F}$
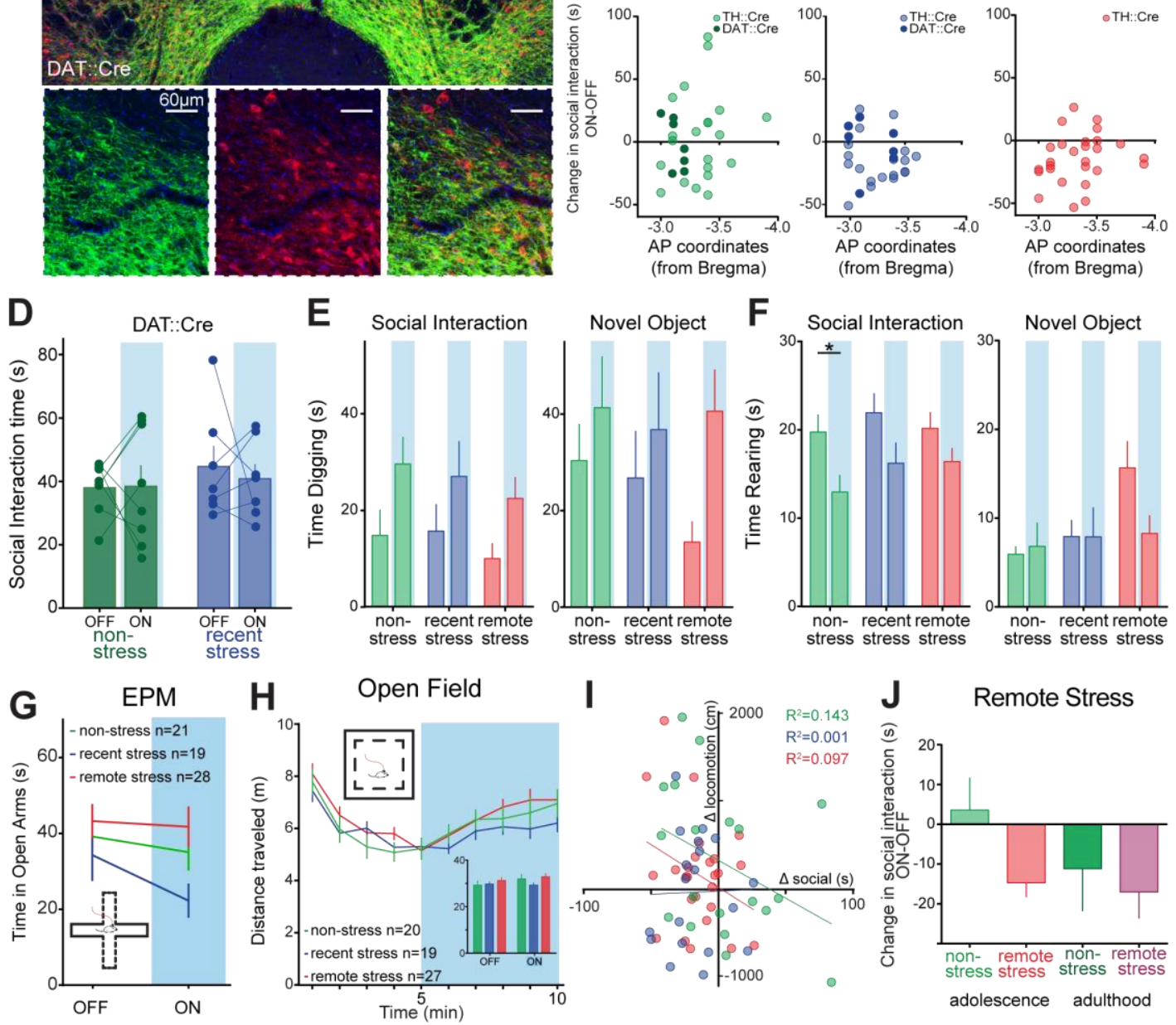
Figure 2 - figure supplement 1

821 (A) Confocal images of a $50 \mu \mathrm{m}$ thick coronal section containing the VTA of a TH::Cre female 822 (upper panels) and a DAT::Cre female (lower panels) injected with AAV 5 -EF1 $\alpha$-DIO-ChR2-eYFP.

823 Thinly dotted white square: localization of the magnified images (40x; DAPI in blue; ChR2-eYFP

824 in green; $\mathrm{TH}$ in red). (B) Histologically verified optical fiber placements for all subjects included in

825 photostimulation experiment. Symbols represent termination of fiber tract for each group. (C)

826 Scatter-plot of anterior-posterior (AP) fiber placement, measured from bregma, vs. social

827 interaction difference scores (ON-OFF) in mice included in study. There was no correlation

828 between AP of fiber placement and social interaction in any of the experimental groups. (D) Effect

829 of photoactivation of VTA DA neurons in DAT::Cre mice in the social interaction assay. (E) There

830 was no effect of stress exposure, or an interaction effect on the time spend digging, however there

831 was a significant effect of light stimulation during both the social interaction (Two-way repeated

832 measures ANOVA, main effect of light: $F_{1,66}=16.82, p=0.0001$; main effect of stress exposure:

$833 F_{2,66}=0.685, p=0.508$; light-by-stress exposure interaction: $F_{2,66}=0.503, p=0.607 ;$ ) and the novel

834 object exploration task (Two-way repeated measures ANOVA, main effect of light: $F_{1,27}=18.34$,

$835 \mathrm{p}=0.0002$; main effect of stress exposure: $F_{2,27}=0.274, p=0.763$; light-by-stress exposure

836 interaction: $\left.F_{2,27}=2.318, p=0.119\right)$. $(F)$ There was no effect of stress exposure, or an interaction

837 effect on the time spend rearing, however there was a significant effect of light stimulation during

838 the social interaction (Two-way repeated measures ANOVA, main effect of light: $F_{1,66}=16.82$,

$839 p=0.0001$; main effect of stress exposure: $F_{2,66}=0.685, p=0.508$; light-by-stress exposure

840 interaction: $F_{2,66}=0.503, p=0.607$ ) but not the novel object exploration task (Two-way repeated

841 measures ANOVA, main effect of light: $F_{1,27}=1.843, p=0.186$; main effect of stress exposure:

$842 \mathrm{~F}_{2,27}=2.008, \mathrm{p}=0.154$; light-by-stress exposure interaction: $\mathrm{F}_{2,27}=2.769, \mathrm{p}=0.081$ ). (G) No

843 significant effect of photoinhibition or stress exposure was observed on open arm exploration in

844 the elevated plus maze assay (Two-way repeated measures ANOVA, main effect of light:

$845 F_{1,65}=3.233, p=0.077$; main effect of stress exposure: $F_{2,65}=2.691, p=0.075$; light-by-stress

846 exposure interaction: $\left.F_{2,65}=0.917, p=0.405\right)$. (H) Photostimulation of VTA DA neurons did not

847 produce a significant light-by-stress exposure interaction in open-field locomotion (Inset: Two-way

848 repeated measures ANOVA comparing summed 0-5 min light-OFF vs. 5-10 min light-ON

849 locomotion by stress exposure interaction, $F_{2,63}=1.072, p=0.349$ ). (I) Photostimulation effects on

850 social interaction ( $\triangle$ social, ON-OFF) did not correlate with photostimulation effects on locomotion

851 ( $\triangle$ locomotion, ON-OFF) in any of the stress exposure groups (Pearson's correlation: non-stress:

$852 r=-0.378, p=0.111$; recent stress: $r=-0.023, p=0.926$; remote stress: $r=-0.311, p=0.122)$. (J) Mice

853 remotely stressed during adulthood $(n=10)$ did not differ in the effect of photoactivation on social 
bioRxiv preprint doi: https://doi.org/10.1101/168492; this version posted July 27,2017 . The copyright holder for this preprint (which was not certified by peer review) is the author/funder, who has granted bioRxiv a license to display the preprint in perpetuity. It is made available under aCC-BY 4.0 International license.

854 interaction compared to mice remotely stressed during adolescence $(n=29)$ tested at the same 855 time ( P155; unpaired t-test: $\left.\mathrm{t}_{37}=0.312, \mathrm{p}=0.757\right)$.

856 
bioRxiv preprint doi: https://doi org/10.1101/168492 this version posted July 27 2017. The copyright holder for this preprint (which was not certified by peer review) is the author/funder, who has granted bioRxiv a license to display the preprint in perpetuity. It is made available under aCC-BY 4.0 International license.

Figure 3- figure supplement 1

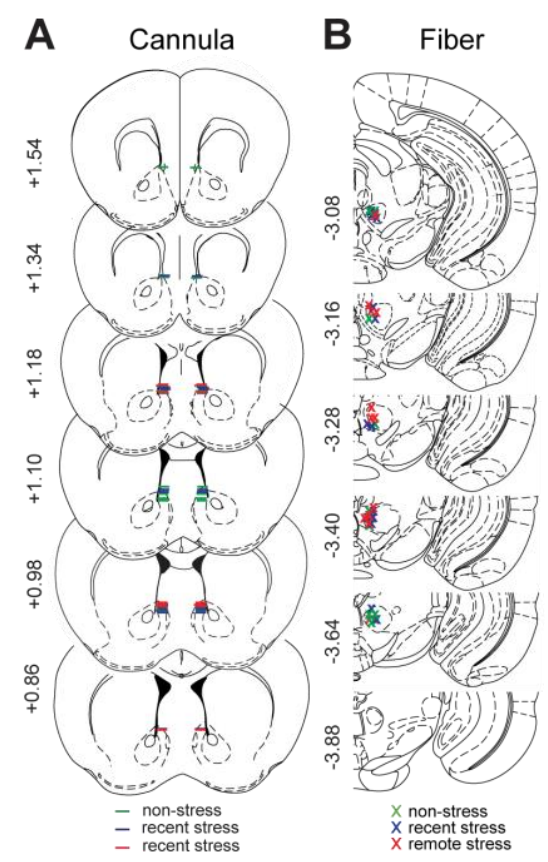

\section{Figure 3 - figure supplement 1}

863 (A) Histologically verified cannulae and (B) optical fiber placements for all subjects included in 864 pharmacology experiments. Symbols represent termination of bilateral cannulae (line) or fiber 865 tract $(\mathrm{x})$ for each stress exposure group.

866

867

868

869

870 
Figure 4 - figure supplement 1

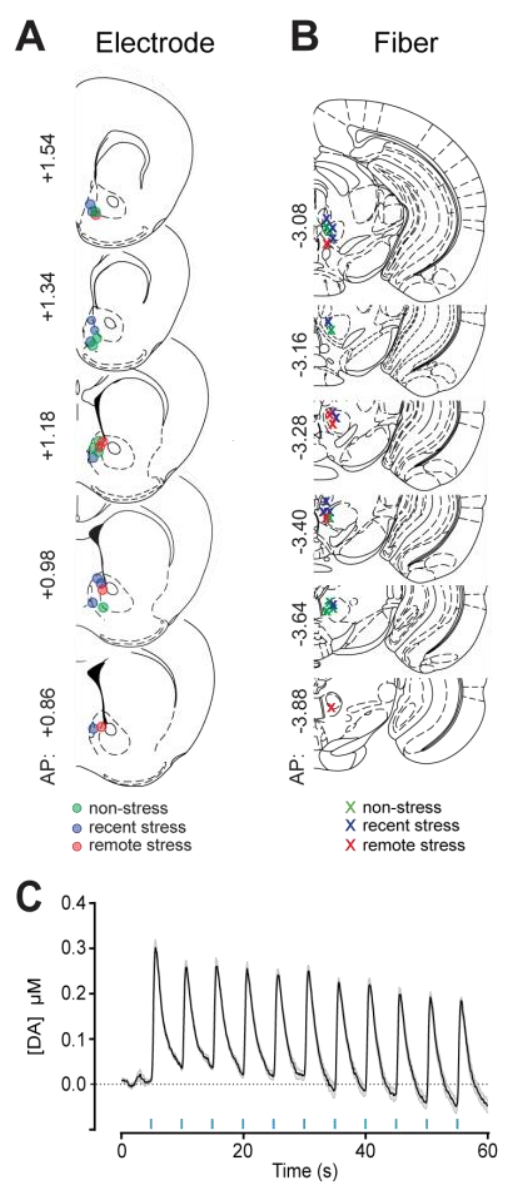

\section{$874 \quad$ Figure 4 - figure supplement 1}

875 (A) Histologically verified carbon fiber electrode and (B) optical fiber placements for all subjects 876 included in the voltammetry experiments. Symbols represent termination of electrode (circle) or 877 optic fiber tract $(\mathrm{x})$ for each stress exposure group. (C) Optical stimulation parameters (eight $5 \mathrm{~ms}$ 878 pulses of blue light delivered at $30 \mathrm{~Hz}$ every $5 \mathrm{~s}$ ) employed during behavioral experiments caused 879 reliable DA release in the NAc. 
Abercrombie, E.D., Keefe, K.A., DiFrischia, D.S., and Zigmond, M.J. (1989). Differential effect of stress on in vivo dopamine release in striatum, nucleus accumbens, and medial frontal cortex. J. Neurochem. 52, $883 \quad 1655-1658$.

884 Afonso, V.M., King, S.J., Novakov, M., Burton, C.L., and Fleming, A.S. (2011). Accumbal dopamine func885 tion in postpartum rats that were raised without their mothers. Horm. Behav. 60, 632-643.

886 Anker, J.J., and Carroll, M.E. (2011). Females are more vulnerable to drug abuse than males: evidence from preclinical studies and the role of ovarian hormones. Curr. Top. Behav. Neurosci. 8, 73-96.

Aragona, B.J., Cleaveland, N.A., Stuber, G.D., Day, J.J., Carelli, R.M., and Wightman, R.M. (2008). Preferential enhancement of dopamine transmission within the nucleus accumbens shell by cocaine is attributable to a direct increase in phasic dopamine release events. J. Neurosci. Off. J. Soc. Neurosci. 28, 8821-8831.

892 Arnsten, A. (1997). Catecholamine regulation of the prefrontal cortex. J Psychopharmacol Oxf Engl 11, 893 151-162.

894 Arnsten, A.F.T. (2009). Stress signalling pathways that impair prefrontal cortex structure and function. 895 Nat. Rev. Neurosci. 10, 410-422.

Badrinarayan, A., Wescott, S.A., Vander Weele, C.M., Saunders, B.T., Couturier, B.E., Maren, S., and Aragona, B.J. (2012). Aversive stimuli differentially modulate real-time dopamine transmission dynamics within the nucleus accumbens core and shell. J. Neurosci. Off. J. Soc. Neurosci. 32, 15779-15790.

Bale, T.L., and Epperson, C.N. (2015). Sex differences and stress across the lifespan. Nat. Neurosci. 18,

901 Bangasser, D.A., and Valentino, R.J. (2014). Sex differences in stress-related psychiatric disorders: neuro902 biological perspectives. Front. Neuroendocrinol. 35, 303-319.

903 Bangasser, D.A., and Wicks, B. (2017). Sex-specific mechanisms for responding to stress. J. Neurosci. Res. $90495,75-82$.

905 Bergan, J.F., Ben-Shaul, Y., and Dulac, C. (2014). Sex-specific processing of social cues in the medial 906 amygdala. ELife 3, e02743.

907 Brady, K.T., and Sinha, R. (2005). Co-occurring mental and substance use disorders: the neurobiological 908 effects of chronic stress. Am. J. Psychiatry 162, 1483-1493.

909 Brake, W.G., Zhang, T.Y., Diorio, J., Meaney, M.J., and Gratton, A. (2004). Influence of early postnatal 910 rearing conditions on mesocorticolimbic dopamine and behavioural responses to psychostimulants and 911 stressors in adult rats. Eur. J. Neurosci. 19, 1863-1874. 
912 Byers, S.L., Wiles, M.V., Dunn, S.L., and Taft, R.A. (2012). Mouse estrous cycle identification tool and im-

913 ages. Plos One 7, e35538.

914 Cabib, S., and Puglisi-Allegra, S. (1996). Different effects of repeated stressful experiences on mesocorti915 cal and mesolimbic dopamine metabolism. Neuroscience 73, 375-380.

916 Cahill, L. (2006). Why sex matters for neuroscience. Nat. Rev. Neurosci. 7, 477-484.

917 Calhoon, G.G., and Tye, K.M. (2015). Resolving the neural circuits of anxiety. Nat. Neurosci. 18, 1394-

9181404.

919 Calipari, E.S., Juarez, B., Morel, C., Walker, D.M., Cahill, M.E., Ribeiro, E., Roman-Ortiz, C., Ramakrishnan, 920 C., Deisseroth, K., Han, M.-H., et al. (2017). Dopaminergic dynamics underlying sex-specific cocaine re921 ward. Nat. Commun. 8, 13877.

922 Campi, K.L., Greenberg, G.D., Kapoor, A., Ziegler, T.E., and Trainor, B.C. (2014). Sex differences in effects 923 of dopamine D1 receptors on social withdrawal. Neuropharmacology 77, 208-216.

924 Cao, J.-L., Covington, H.E., Friedman, A.K., Wilkinson, M.B., Walsh, J.J., Cooper, D.C., Nestler, E.J., and 925 Han, M.-H. (2010). Mesolimbic dopamine neurons in the brain reward circuit mediate susceptibility to 926 social defeat and antidepressant action. J. Neurosci. Off. J. Soc. Neurosci. 30, 16453-16458.

927 Carola, V., D'Olimpio, F., Brunamonti, E., Mangia, F., and Renzi, P. (2002). Evaluation of the elevated 928 plus-maze and open-field tests for the assessment of anxiety-related behaviour in inbred mice. Behav.

929 Brain Res. 134, 49-57.

930 Carpenter, T., Grecian, S.M., and Reynolds, R.M. (2017). Sex differences in early-life programming of the 931 hypothalamic-pituitary-adrenal axis in humans suggest increased vulnerability in females: a systematic 932 review. J. Dev. Orig. Health Dis. 1-12.

933 Chaudhury, D., Walsh, J.J., Friedman, A.K., Juarez, B., Ku, S.M., Koo, J.W., Ferguson, D., Tsai, H.-C., Pom934 eranz, L., Christoffel, D.J., et al. (2013). Rapid regulation of depression-related behaviours by control of 935 midbrain dopamine neurons. Nature 493, 532-536.

936 Chetty, S., Friedman, A.R., Taravosh-Lahn, K., Kirby, E.D., Mirescu, C., Guo, F., Krupik, D., Nicholas, A., 937 Geraghty, A.C., Krishnamurthy, A., et al. (2014). Stress and glucocorticoids promote oligodendrogenesis 938 in the adult hippocampus. Mol. Psychiatry 19, 1275-1283.

939 Chrousos, G.P. (2009). Stress and disorders of the stress system. Nat. Rev. Endocrinol. 5, 374-381.

940 Dalla, C., Antoniou, K., Drossopoulou, G., Xagoraris, M., Kokras, N., Sfikakis, A., and Papadopoulou941 Daifoti, Z. (2005). Chronic mild stress impact: are females more vulnerable? Neuroscience 135, 703-714.

942 Day, J.J., Roitman, M.F., Wightman, R.M., and Carelli, R.M. (2007). Associative learning mediates dy-

943 namic shifts in dopamine signaling in the nucleus accumbens. Nat. Neurosci. 10, 1020-1028. 
944 Di Chiara, G., Loddo, P., and Tanda, G. (1999). Reciprocal changes in prefrontal and limbic dopamine re-

945 sponsiveness to aversive and rewarding stimuli after chronic mild stress: implications for the psychobiol-

946 ogy of depression. Biol. Psychiatry 46, 1624-1633.

947 Dube, S.R., Felitti, V.J., Dong, M., Chapman, D.P., Giles, W.H., and Anda, R.F. (2003). Childhood abuse, 948 neglect, and household dysfunction and the risk of illicit drug use: the adverse childhood experiences

949 study. Pediatrics 111, 564-572.

950 Duchesne, A., Dufresne, M.M., and Sullivan, R.M. (2009). Sex differences in corticolimbic dopamine and 951 serotonin systems in the rat and the effect of postnatal handling. Prog. Neuropsychopharmacol. Biol.

952 Psychiatry 33, 251-261.

953 Dulac, C., and Kimchi, T. (2007). Neural mechanisms underlying sex-specific behaviors in vertebrates.

954 Curr. Opin. Neurobiol. 17, 675-683.

955 Felix-Ortiz, A.C., and Tye, K.M. (2014). Amygdala inputs to the ventral hippocampus bidirectionally mod956 ulate social behavior. J. Neurosci. Off. J. Soc. Neurosci. 34, 586-595.

957 Felix-Ortiz, A.C., Burgos-Robles, A., Bhagat, N.D., Leppla, C.A., and Tye, K.M. (2016). Bidirectional modu958 lation of anxiety-related and social behaviors by amygdala projections to the medial prefrontal cortex. 959 Neuroscience 321, 197-209.

960 Fone, K.C.F., and Porkess, M.V. (2008). Behavioural and neurochemical effects of post-weaning social 961 isolation in rodents-relevance to developmental neuropsychiatric disorders. Neurosci. Biobehav. Rev.

$96232,1087-1102$.

963 Goel, N., and Bale, T.L. (2009). Examining the intersection of sex and stress in modelling neuropsychiatric 964 disorders. J. Neuroendocrinol. 21, 415-420.

965 Gold, P.W. (2015). The organization of the stress system and its dysregulation in depressive illness. Mol.

966 Psychiatry 20, 32-47.

967 Gruene, T.M., Flick, K., Stefano, A., Shea, S.D., and Shansky, R.M. (2015). Sexually divergent expression

968 of active and passive conditioned fear responses in rats. ELife 4.

969 Gunaydin, L.A., Grosenick, L., Finkelstein, J.C., Kauvar, I.V., Fenno, L.E., Adhikari, A., Lammel, S., Mir970 zabekov, J.J., Airan, R.D., Zalocusky, K.A., et al. (2014). Natural neural projection dynamics underlying 971 social behavior. Cell 157, 1535-1551.

972 Handa, R.J., Burgess, L.H., Kerr, J.E., and O'Keefe, J.A. (1994). Gonadal steroid hormone receptors and 973 sex differences in the hypothalamo-pituitary-adrenal axis. Horm. Behav. 28, 464-476.

974 Haney, M., Maccari, S., Le Moal, M., Simon, H., and Piazza, P.V. (1995). Social stress increases the acqui975 sition of cocaine self-administration in male and female rats. Brain Res. 698, 46-52.

976 Holly, E.N., and Miczek, K.A. (2016). Ventral tegmental area dopamine revisited: effects of acute and re977 peated stress. Psychopharmacology (Berl.) 233, 163-186. 
Holly, E.N., Shimamoto, A., Debold, J.F., and Miczek, K.A. (2012). Sex differences in behavioral and neural cross-sensitization and escalated cocaine taking as a result of episodic social defeat stress in rats. Psychopharmacology (Berl.) 224, 179-188.

981 Imperato, A., Angelucci, L., Casolini, P., Zocchi, A., and Puglisi-Allegra, S. (1992). Repeated stressful expe982 riences differently affect limbic dopamine release during and following stress. Brain Res. 577, $194-199$.

Johnston, J.H., Linden, D.E.J., and van den Bree, M.B.M. (2016). Combining Stress and Dopamine Based Models of Addiction: Towards a Psycho-Neuro-Endocrinological Theory of Addiction. Curr. Drug Abuse

985 Rev. 9, 61-74.

Kalivas, P.W., and Duffy, P. (1995). Selective activation of dopamine transmission in the shell of the nucleus accumbens by stress. Brain Res. 675, 325-328.

988 Karkhanis, A.N., Rose, J.H., Weiner, J.L., and Jones, S.R. (2016). Early-Life Social Isolation Stress Increases 989 Kappa Opioid Receptor Responsiveness and Downregulates the Dopamine System. Neuropsychophar990 macol. Off. Publ. Am. Coll. Neuropsychopharmacol. 41, 2263-2274.

991 Kessler, R.C. (2003). Epidemiology of women and depression. J. Affect. Disord. 74, 5-13.

992 Kessler, R.C., McGonagle, K.A., Zhao, S., Nelson, C.B., Hughes, M., Eshleman, S., Wittchen, H.U., and 993 Kendler, K.S. (1994). Lifetime and 12-month prevalence of DSM-III-R psychiatric disorders in the United 994 States. Results from the National Comorbidity Survey. Arch. Gen. Psychiatry 51, 8-19.

995 Koenig, J.I., Walker, C.-D., Romeo, R.D., and Lupien, S.J. (2011). Effects of stress across the lifespan. 996 Stress Amst. Neth. 14, 475-480.

997 Koob, G.F., and Volkow, N.D. (2016). Neurobiology of addiction: a neurocircuitry analysis. Lancet Psychi998 atry $3,760-773$.

999 Krishnan, V., Han, M.-H., Graham, D.L., Berton, O., Renthal, W., Russo, S.J., Laplant, Q., Graham, A., Lut1000 ter, M., Lagace, D.C., et al. (2007). Molecular adaptations underlying susceptibility and resistance to so1001 cial defeat in brain reward regions. Cell 131, 391-404.

1002 Laman-Maharg, A., and Trainor, B.C. (2017). Stress, sex, and motivated behaviors. J. Neurosci. Res. 95, 1003 83-92.

1004 Lammel, S., Ion, D.I., Roeper, J., and Malenka, R.C. (2011). Projection-Specific Modulation of Dopamine 1005 Neuron Synapses by Aversive and Rewarding Stimuli. Neuron 70, 855-862.

1006 Lammel, S., Lim, B.K., Ran, C., Huang, K.W., Betley, M.J., Tye, K.M., Deisseroth, K., and Malenka, R.C. 1007 (2012). Input-specific control of reward and aversion in the ventral tegmental area. Nature 491, 2121008217.

1009 Lammel, S., Steinberg, E.E., Földy, C., Wall, N.R., Beier, K., Luo, L., and Malenka, R.C. (2015). Diversity of 1010 transgenic mouse models for selective targeting of midbrain dopamine neurons. Neuron 85, 429-438. 
1011 Lapiz, M.D.S., Fulford, A., Muchimapura, S., Mason, R., Parker, T., and Marsden, C.A. (2003). Influence of 1012 postweaning social isolation in the rat on brain development, conditioned behavior, and neurotransmis1013 sion. Neurosci. Behav. Physiol. 33, 13-29.

1014 Lemos, J.C., Wanat, M.J., Smith, J.S., Reyes, B.A.S., Hollon, N.G., Van Bockstaele, E.J., Chavkin, C., and 1015 Phillips, P.E.M. (2012). Severe stress switches CRF action in the nucleus accumbens from appetitive to 1016 aversive. Nature 490, 402-406.

1017 Lin, Y., Westenbroek, C., Bakker, P., Termeer, J., Liu, A., Li, X., and Ter Horst, G.J. (2008). Effects of long1018 term stress and recovery on the prefrontal cortex and dentate gyrus in male and female rats. Cereb. Cor1019 tex N. Y. N 1991 18, 2762-2774.

1020 Logrip, M.L., Zorrilla, E.P., and Koob, G.F. (2012). Stress modulation of drug self-administration: implica1021 tions for addiction comorbidity with post-traumatic stress disorder. Neuropharmacology 62, 552-564.

1022 Lovic, V., Fleming, A.S., and Fletcher, P.J. (2006). Early life tactile stimulation changes adult rat respon1023 siveness to amphetamine. Pharmacol. Biochem. Behav. 84, 497-503.

1024

1025

1026

1027 1028

1029

1030

1031

1032

1033

1034

1035

1036 1037

1038

1039

1040

1041

1042

1043

Lowery, E.G., Sparrow, A.M., Breese, G.R., Knapp, D.J., and Thiele, T.E. (2008). The CRF-1 receptor antagonist, CP-154,526, attenuates stress-induced increases in ethanol consumption by BALB/cJ mice. Alcohol. Clin. Exp. Res. 32, 240-248.

Luine, V. (2002). Sex differences in chronic stress effects on memory in rats. Stress Amst. Neth. 5, 205216.

Mah, L., Szabuniewicz, C., and Fiocco, A.J. (2016). Can anxiety damage the brain? Curr. Opin. Psychiatry 29, 56-63.

Mantz, J., Thierry, A.M., and Glowinski, J. (1989). Effect of noxious tail pinch on the discharge rate of mesocortical and mesolimbic dopamine neurons: selective activation of the mesocortical system. Brain Res. 476, 377-381.

Marcondes, F.K., Bianchi, F.J., and Tanno, A.P. (2002). Determination of the estrous cycle phases of rats: some helpful considerations. Braz. J. Biol. Rev. Brasleira Biol. 62, 609-614.

Matthews, G. (2016). Dorsal Raphe Dopamine Neurons Represent the Experience of Social Isolation. Cell $164,617-631$.

Matthews, K., and Robbins, T.W. (2003). Early experience as a determinant of adult behavioural responses to reward: the effects of repeated maternal separation in the rat. Neurosci. Biobehav. Rev. 27, 45-55.

Matthews, G.A., Nieh, E.H., Vander Weele, C.M., Halbert, S.A., Pradhan, R.V., Yosafat, A.S., Glober, G.F., Izadmehr, E.M., Thomas, R.E., Lacy, G.D., et al. (2016). Dorsal Raphe Dopamine Neurons Represent the Experience of Social Isolation. Cell 164, 617-631. 
1044 McEwen, B.S., Bowles, N.P., Gray, J.D., Hill, M.N., Hunter, R.G., Karatsoreos, I.N., and Nasca, C. (2015).

1045 Mechanisms of stress in the brain. Nat. Neurosci. 18, 1353-1363.

1046 Nestler, E.J., and Carlezon, W.A. (2006). The mesolimbic dopamine reward circuit in depression. Biol.

1047 Psychiatry 59, 1151-1159.

1048 Nieh, E.H., Vander Weele, C.M., Matthews, G.A., Presbrey, K.N., Wichmann, R., Leppla, C.A., Izadmehr, 1049 E.M., and Tye, K.M. (2016). Inhibitory Input from the Lateral Hypothalamus to the Ventral Tegmental

1050 Area Disinhibits Dopamine Neurons and Promotes Behavioral Activation. Neuron 90, 1286-1298.

1051 Niesink, R.J.M., and Van Ree, J.M. (1982). Short-term isolation increases social interactions of male rats:

1052 A parametric analysis. Physiol. Behav. 29, 819-825.

1053 Panksepp, J., and Beatty, W.W. (1980). Social deprivation and play in rats. Behav. Neural Biol. 30, 197-

1054206.

1055 Pattwell, S.S., Duhoux, S., Hartley, C.A., Johnson, D.C., Jing, D., Elliott, M.D., Ruberry, E.J., Powers, A., 1056 Mehta, N., Yang, R.R., et al. (2012). Altered fear learning across development in both mouse and human.

1057 Proc. Natl. Acad. Sci. 109, 16318-16323.

1058 Pellow, S., Chopin, P., File, S.E., and Briley, M. (1985). Validation of open : closed arm entries in an ele1059 vated plus-maze as a measure of anxiety in the rat. J. Neurosci. Methods 14, 149-167.

1060 Phillips, P.E.M., Stuber, G.D., Heien, M.L.A.V., Wightman, R.M., and Carelli, R.M. (2003). Subsecond do1061 pamine release promotes cocaine seeking. Nature 422, 614-618.

1062 Piazza, P.V., and Le Moal, M. (1998). The role of stress in drug self-administration. Trends Pharmacol. 1063 Sci. 19, 67-74.

1064 Piazza, P.V., and Le Moal, M.L. (1996). Pathophysiological basis of vulnerability to drug abuse: role of an 1065 interaction between stress, glucocorticoids, and dopaminergic neurons. Annu. Rev. Pharmacol. Toxicol. $106636,359-378$.

1067 Preller, K.H., Herdener, M., Schilbach, L., Stämpfli, P., Hulka, L.M., Vonmoos, M., Ingold, N., Vogeley, K., 1068 Tobler, P.N., Seifritz, E., et al. (2014). Functional changes of the reward system underlie blunted re1069 sponse to social gaze in cocaine users. Proc. Natl. Acad. Sci. U. S. A. 111, 2842-2847.

1070 Robinson, D.L., Heien, M.L.A.V., and Wightman, R.M. (2002). Frequency of dopamine concentration 1071 transients increases in dorsal and ventral striatum of male rats during introduction of conspecifics. J. 1072 Neurosci. Off. J. Soc. Neurosci. 22, 10477-10486.

1073 Roitman, M.F., Stuber, G.D., Phillips, P.E.M., Wightman, R.M., and Carelli, R.M. (2004). Dopamine oper1074 ates as a subsecond modulator of food seeking. J. Neurosci. Off. J. Soc. Neurosci. 24, 1265-1271.

1075 Roitman, M.F., Wheeler, R.A., Wightman, R.M., and Carelli, R.M. (2008). Real-time chemical responses in 1076 the nucleus accumbens differentiate rewarding and aversive stimuli. Nat. Neurosci. 11, 1376-1377. 
1077 Russo, S.J., and Nestler, E.J. (2013). The Brain Reward Circuitry in Mood Disorders. Nat. Rev. Neurosci.

107814.

1079 Saal, D., Dong, Y., Bonci, A., and Malenka, R.C. (2003). Drugs of abuse and stress trigger a common syn1080 aptic adaptation in dopamine neurons. Neuron 37, 577-582.

1081 Sandi, C., and Haller, J. (2015). Stress and the social brain: behavioural effects and neurobiological mech1082 anisms. Nat. Rev. Neurosci. 16, 290-304.

1083 Schneiderman, N., Ironson, G., and Siegel, S.D. (2005). STRESS AND HEALTH: Psychological, Behavioral, 1084 and Biological Determinants. Annu. Rev. Clin. Psychol. 1, 607-628.

1085 Schultz, W. (1998). Predictive reward signal of dopamine neurons. J. Neurophysiol. 80, 1-27.

1086 Shaham, Y., Shalev, U., Lu, L., De Wit, H., and Stewart, J. (2003). The reinstatement model of drug re1087 lapse: history, methodology and major findings. Psychopharmacology (Berl.) 168, 3-20.

1088 Shansky, R.M., and Lipps, J. (2013). Stress-induced cognitive dysfunction: hormone-neurotransmitter in1089 teractions in the prefrontal cortex. Front. Hum. Neurosci. 7, 123.

1090 Shimamoto, A., Debold, J.F., Holly, E.N., and Miczek, K.A. (2011). Blunted accumbal dopamine response 1091 to cocaine following chronic social stress in female rats: exploring a link between depression and drug 1092 abuse. Psychopharmacology (Berl.) 218, 271-279.

1093 Shimamoto, A., Holly, E.N., Boyson, C.O., DeBold, J.F., and Miczek, K.A. (2015). Individual differences in 1094 anhedonic and accumbal dopamine responses to chronic social stress and their link to cocaine self-ad1095 ministration in female rats. Psychopharmacology (Berl.) 232, 825-834.

1096 Sinha, R. (2008). Chronic stress, drug use, and vulnerability to addiction. Ann. N. Y. Acad. Sci. 1141, 1051097130.

1098 Solomon, M.B. (2017). Evaluating social defeat as a model for psychopathology in adult female rodents. 1099 J. Neurosci. Res. 95, 763-776.

1100 Stuber, G.D., Stamatakis, A.M., and Kantak, P.A. (2015). Considerations when using cre-driver rodent 1101 lines for studying ventral tegmental area circuitry. Neuron 85, 439-445.

1102 Taylor, S.E., Klein, L.C., Lewis, B.P., Gruenewald, T.L., Gurung, R.A., and Updegraff, J.A. (2000). Biobehav1103 ioral responses to stress in females: tend-and-befriend, not fight-or-flight. Psychol. Rev. 107, 411-429.

1104 Ter Horst, G.J., Wichmann, R., Gerrits, M., Westenbroek, C., and Lin, Y. (2009). Sex differences in stress 1105 responses: focus on ovarian hormones. Physiol. Behav. 97, 239-249.

1106 Thierry, A.M., Tassin, J.P., Blanc, G., and Glowinski, J. (1976). Selective activation of mesocortical DA sys1107 tem by stress. Nature 263, 242-244. 
1108 Thomas, M.B., Hu, M., Lee, T.M., Bhatnagar, S., and Becker, J.B. (2009). Sex-specific susceptibility to cocaine in rats with a history of prenatal stress. Physiol. Behav. 97, 270-277.

1110 Tidey, J.W., and Miczek, K.A. (1996). Social defeat stress selectively alters mesocorticolimbic dopamine 1111 release: an in vivo microdialysis study. Brain Res. 721, 140-149.

1112 Trainor, B.C. (2011). Stress responses and the mesolimbic dopamine system: social contexts and sex dif1113 ferences. Horm. Behav. 60, 457-469.

1114 Trainor, B.C., Pride, M.C., Villalon Landeros, R., Knoblauch, N.W., Takahashi, E.Y., Silva, A.L., and Crean, 1115 K.K. (2011). Sex differences in social interaction behavior following social defeat stress in the monoga1116 mous California mouse (Peromyscus californicus). PloS One 6, e17405.

1117 Tye, K.M., Mirzabekov, J.J., Warden, M.R., Ferenczi, E.A., Tsai, H.-C., Finkelstein, J., Kim, S.-Y., Adhikari, 1118 A., Thompson, K.R., Andalman, A.S., et al. (2013). Dopamine neurons modulate neural encoding and ex1119 pression of depression-related behaviour. Nature 493, 537-541.

1120 Valenti, O., Gill, K.M., and Grace, A.A. (2012). Different stressors produce excitation or inhibition of 1121 mesolimbic dopamine neuron activity: response alteration by stress pre-exposure. Eur. J. Neurosci. 35, $1122 \quad 1312-1321$.

1123 Varlinskaya, E.I., Spear, L.P., and Spear, N.E. (1999). Social Behavior and Social Motivation in Adolescent 1124 Rats: Role of Housing Conditions and Partner's Activity. Physiol. Behav. 67, 475-482.

1125 Volkow, N.D., Baler, R.D., and Goldstein, R.Z. (2011). Addiction: pulling at the neural threads of social 1126 behaviors. Neuron 69, 599-602.

1127 Wightman, R.M., and Robinson, D.L. (2002). Transient changes in mesolimbic dopamine and their associ1128 ation with "reward." J. Neurochem. 82, 721-735.

1129 Wise, R.A. (2008). Dopamine and reward: The anhedonia hypothesis 30 years on. Neurotox. Res. 14, $1130 \quad 169-183$.

1131 Witten, I.B., Steinberg, E.E., Lee, S.Y., Davidson, T.J., Zalocusky, K.A., Brodsky, M., Yizhar, O., Cho, S.L., 1132 Gong, S., Ramakrishnan, C., et al. (2011). Recombinase-Driver Rat Lines: Tools, Techniques, and Optoge1133 netic Application to Dopamine-Mediated Reinforcement. Neuron 72, 721-733.

1134 Yerkes, R.M., and Dodson, J.D. (1908). The relation of strength of stimulus to rapidity of habit-formation. 1135 J. Comp. Neurol. Psychol. 18, 459-482.

1136 Yorgason, J.T., España, R.A., Konstantopoulos, J.K., Weiner, J.L., and Jones, S.R. (2013). Enduring in1137 creases in anxiety-like behavior and rapid nucleus accumbens dopamine signaling in socially isolated 1138 rats. Eur. J. Neurosci. 37, 1022-1031.

1139 Yorgason, J.T., Calipari, E.S., Ferris, M.J., Karkhanis, A.N., Fordahl, S.C., Weiner, J.L., and Jones, S.R. 1140 (2016). Social isolation rearing increases dopamine uptake and psychostimulant potency in the striatum. 1141 Neuropharmacology 101, 471-479. 
bioRxiv preprint doi: https://doi.org/10.1101/168492; this version posted July 27, 2017. The copyright holder for this preprint (which was not certified by peer review) is the author/funder, who has granted bioRxiv a license to display the preprint in perpetuity. It is made available under aCC-BY 4.0 International license.

1142 